\title{
Photobiocatalysis: The power of combining photocatalysis and enzymes.
}

Juan Antonio Maciá-Agulló, Avelino Corma and Hermenegildo Garcia.

Instituto Universitario de Tecnología Química CSIC-UPV, Universidad Politécnica de Valencia, Av. De los Naranjos s/n, 46022, Valencia, Spain.

\section{Abstract}

Photobiocatalysts are constituted by a semiconductor with or without light harvester that activates an enzyme. A logical source of inspiration for the development of photobiocatalysts has been natural photosynthetic centers. In photobiocatalysis, the coupling of the semiconductor and the enzyme frequently requires of the natural cofactor and a relay transferring charge carriers from the semiconductor. The most widely studied photobiocatalysts so far make use of conduction band electrons of excited semiconductor to promote enzymatic reductions mediated by $\mathrm{NAD}^{+} / \mathrm{NADH}$ and an electron relay. The present review presents the state of the art in the field and has been organized based on the semiconductor and the reaction type including oxidations, hydrogen generation, $\mathrm{CO}_{2}$ reduction. The possibility of direct enzyme activation by the semiconductor and the influence of the nature of mediator are also discussed as well as the use of mimics of enzyme active center in combination with the semiconductor. The final section summarizes the state of the art of photobiocatalysis and comments on our view on future developments of the field.

\section{Introduction}

Green algae and plants have developed during evolution a very complex machinery to convert sunlight into biochemical energy in the form of $\mathrm{NADH}, \mathrm{FADH}_{2}$ and other reducing agents as well as glucose and biomolecules from $\mathrm{CO}_{2} \cdot{ }^{[1]}$ This complex biochemical system requires a platform (thylakoids) acting as scaffold to immobilize and arrange in the space all the individual components of the photosynthetic system. Moreover, a notable feature of the natural photosynthetic system is that light is absorbed in two different centers (PSI and PSII) that operate synchronously by transferring electrons from PSII to PSI system through the cytochrome complex connecting them. ${ }^{[2]}$ Scheme 1 illustrates a simplified operation mechanism of the photosynthetic centers. In conventional photocatalysis using inorganic semiconductors, this type of configuration and two photons coupled process is denoted as Zscheme. ${ }^{[3,4]}$ The term $Z$ derives from the shape of the common schematic representation of two photon excitations rendering independently electrons and holes in two different 
semiconductors and the transfer of one electron from the conduction band of one semiconductor to the valence band of the other (Scheme 2).

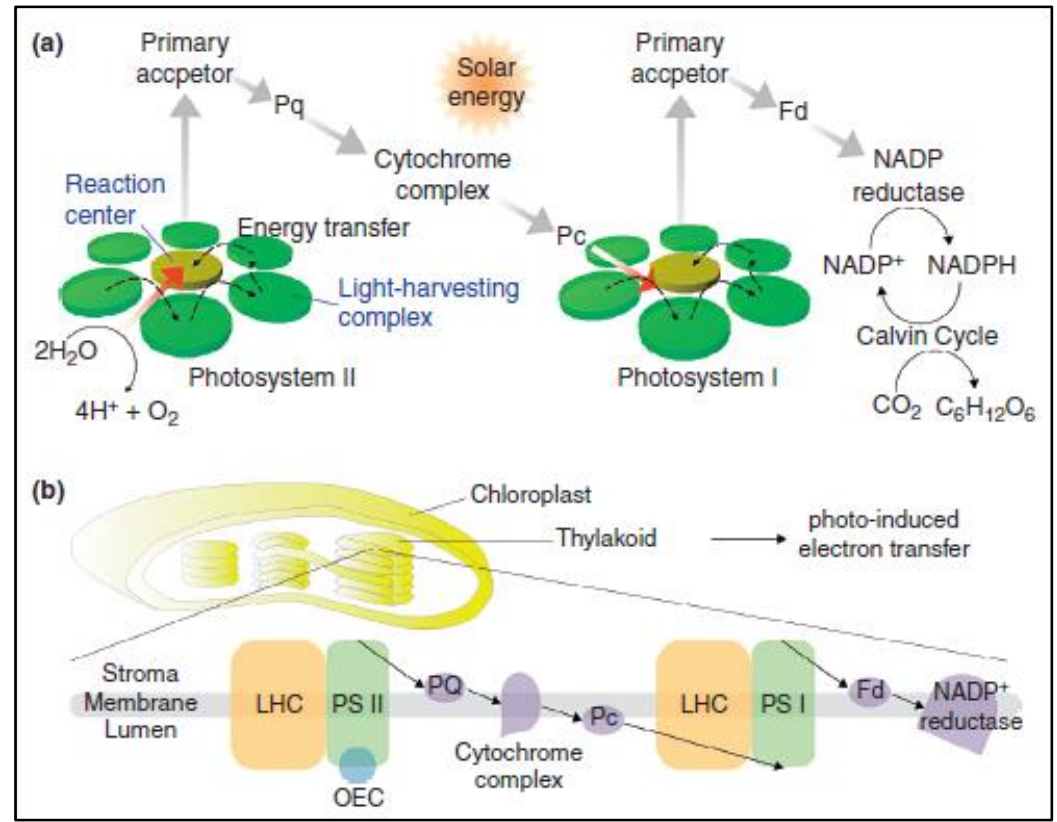

Scheme 1. Simplified description of the components and operation mechanism of the natural photosynthetic system with two photoresponsive centers (PS) connected through the cytochrome complex transferring electrons from PSII to PSI. Note that in PSII water oxidation takes place, while in PSI highly reducing species are generated. LHC: light harvesting centers, PS: photosynthetic site, Fd: ferredoxin. (Figure taken with permission from ref ${ }^{[2]}$ ).

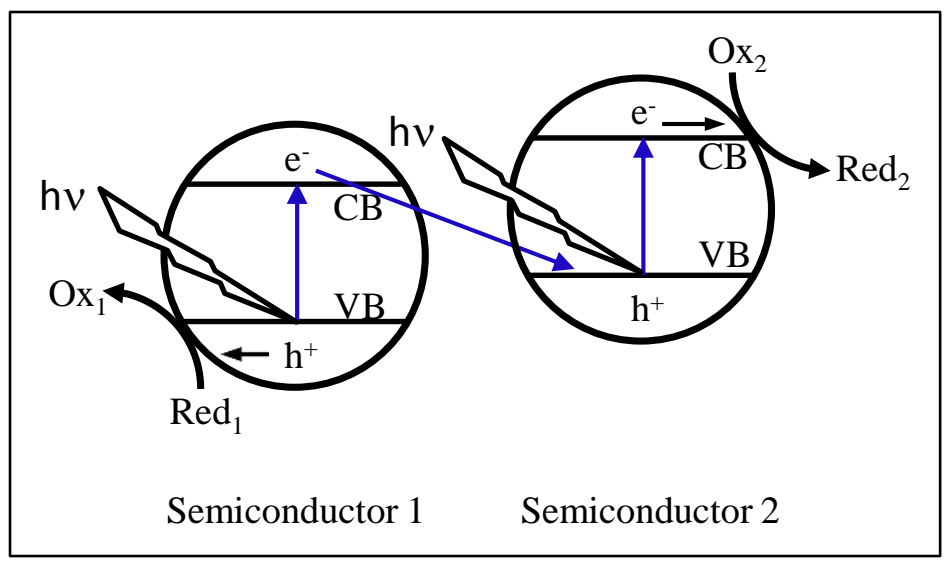

Scheme 2. Illustration and simplified operation mechanism of the Z-scheme where electron transfer in a semiconductor 1-semiconductor 2 composite takes place upon synchronous excitation of the two semiconductors. The driving force for electron transfer is the difference in the energy levels between the two semiconductors. After the transfer, holes and electrons are located in different particles. 
In spite of the potential advantages, artificial Z-schemes based on semiconductors have been found to operate not very efficiently so $f a r .{ }^{[2]}$ This inefficient operation of the artificial Zscheme using inorganic semiconductors is due not only to the need of generation of similar number of electrons and holes in the two semiconductors with also similar reaction rates, but, more importantly, the limitation derives from the coupling of the two semiconductors. One general strategy for this coupling between the semiconductor particles is the use of electrolyte with a redox system in suspension. However, in order to be efficient the redox pair of the electrolyte should selectively take electrons from one semiconductor, delivering them to the second one (Z-scheme), without making other redox processes, also possible. In the absence of electrolyte, the Z-scheme should operate through the junction between the solid particles of the two semiconductors, a process that also takes place with low yield. As consequence in the present state of the art of photocatalysis, photobiocatalytic systems have to operate mostly with absorption of a single photon on a single photocatalyst, there being a large interest and potential in applying efficient Z-scheme as in natural photosynthetic systems.

Photobiocatalytic systems can be broadly defined as those photocatalytic systems comprising an enzyme and/or the corresponding cofactors and mediators that could allow operation of an enzymatic system. ${ }^{[5-7]}$ According with the previous comments on the inefficacy of $Z$ scheme, most of the current photobiocatalytic systems are limited to four elements that, in principle, should be present an aqueous media exposed to the light and lacking of any spatial structuring among them that is another feature of the natural photosynthetic system that still remains to be mimicked adequately. These four components include two active materials, the photocatalyst and the enzyme, and at least two chemical compounds that should act as sacrificial donor and electron relay between the photocatalyst and the enzyme, respectively. Additionally, the presence of a cofactor recognized by the enzyme may also be necessary. Scheme 3 depicts the components of a photobiocatalyst.

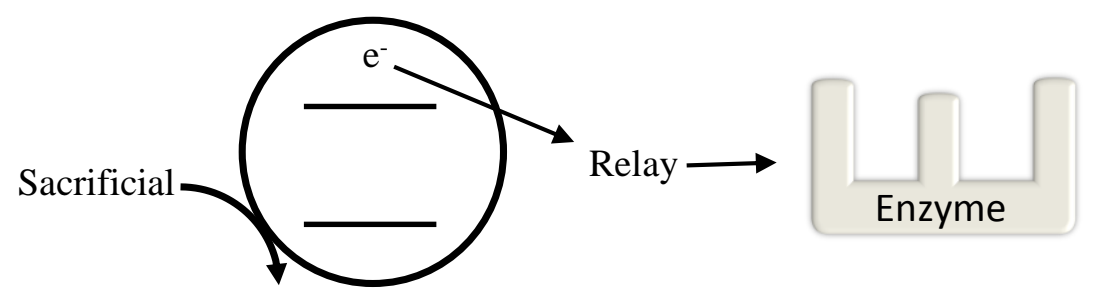

Semiconductor

Scheme 3. Illustration of the four components that are required in photobiocatalytic systems. 
Most commonly, the sacrificial donors should give electrons to the photocatalyst in the state of charge separation and, similarly to PSI natural photocatalytic systems, it should leave electrons with high reduction potential on the conduction band of the semiconductor available to be transferred to the enzyme by means of the mediator or the combination of a mediator and a cofactor. In a few of the reported examples, the sacrificial electron donor is, like in the natural photosynthesis, water and, then, oxygen should be the final resulting byproduct from the electron transfer to the photocatalyst as in the natural photosynthetic center PSII. However, due to its high oxidation potential, these are more efficient electron donors than water, such as alcohols, tertiary amines including ethylendiamine tetraacetate and even sulfur compounds. Thus, according to the previous comments, in the most common photobiocatalytic systems the mediator should accept electrons and, therefore, most common enzymes operate promoting reductions in substrates by means of reductases. This is also the situation of natural photosynthetic center PSI where $\mathrm{CO}_{2}$ reduction is taking place.

Since besides quenching electrons from the conduction band of the semiconductor mediators have to act as cofactors for the enzyme, the choice of mediator is so far very limited and there is a lack of predictive capability on the mediator structure. Basically the two natural cofactors that act as ubiquitous reducing agents in natural biochemical routes are NADPH and $\mathrm{FADH}_{2} \cdot{ }^{\left[{ }^{8,9]}\right.}$ While these two natural mediators act as cofactors in many enzymes, the problem arises from their poor quenching ability to accept electrons from the conduction band of semiconductors, particularly from $\mathrm{TiO}_{2}$. To solve this problem, an electron relay acting as mediator of electrons from the photocatalyst particle to the cofactor has to be present as an additional component in the system. Mediators are not present in natural biochemical systems, but are most frequently required in photobiocatalysis as relays between the photocatalyst and the enzymatic system. Considering that reductions are the most common processes in the current state of the art in photobiocatalysis, the role of the mediator is to trap efficiently electrons from semiconductor conduction band and promote the reduction of the oxidized form of the cofactor recognized by the enzyme. Even for mediators, their choice is limited at the present and Rh-based organometallic complexes are among the most general and widely used. However, the high cost of Rh metal combined with the need of dedicated synthesis to obtain the organometallic complexes make this relay notoriously unsatisfactory, there being a need of expanding the number of mediators. Scheme 4 summarises the role and operation of mediators in a photocatalytic system. 


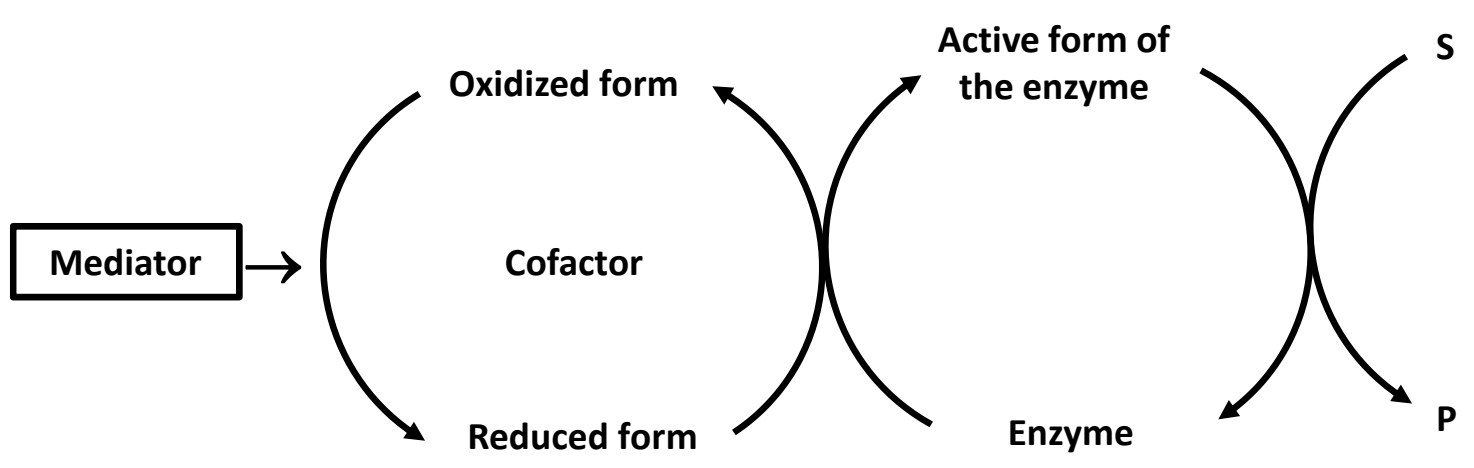

Scheme 4. Role of mediator acting as efficient electron relay from the photocatalyst in the charge separate state and transferring it to the cofactor recognized by the enzyme.

\section{Enzymes in the characterisation of the reaction mechanism}

Photobiocatalysis with specific enzymes can be used to gain insight into the reaction mechanism of photocatalytic reactions. In this way, Pichat and coworkers have used catalase and superoxide dismutase to address the nature of the active reactive oxygen species (ROS) responsible for the decomposition of the organic pollutants. ${ }^{[10]}$ When photocatalysis is carried out in the presence of $\mathrm{O}_{2}$, either in the gas phase or even in aqueous solution where the $\mathrm{O}_{2}$ concentration at atmospheric pressure and room temperature is submillimolar ( $8 \mathrm{ppm})$, the most efficient electron acceptor of conduction band electrons is always $\mathrm{O}_{2}$ due to the ease of this molecule to undergo reduction. Single electron reduction of $\mathrm{O}_{2}$ leads initially to $\mathrm{O}_{2}{ }^{-}$ superoxide that upon protonation and further reduction and protonation forms readily $\mathrm{H}_{2} \mathrm{O}_{2}$ (Equation 1). From the conceptual point of view, and considering the vast number of possible ROS, including ozone, singlet oxygen, hydroxyl radicals, etc, it is important to determine which of all these ROS play the major role in the photocatalytic, oxidative degradation of pollutants.

$$
\mathrm{O}_{2} \stackrel{\mathrm{e}_{\mathrm{CB}}^{-}}{\rightarrow} \mathrm{O}_{2}^{-} \stackrel{\mathrm{H}^{+}}{\rightarrow} \mathrm{H}-\mathrm{O}-\mathrm{O} \stackrel{\cdot \mathrm{e}^{-}}{\rightarrow} \mathrm{H}-\mathrm{O}-\mathrm{O} \stackrel{-\mathrm{H}^{+}}{\rightarrow} \mathrm{HOOH}(1)
$$

In this context, using 1,2-dimethoxybenzene as model pollutant and $\mathrm{TiO}_{2}$ and $\mathrm{ZnO}$ as semiconductors, two enzymes were used to determine their influence on its disappearance by intercepting selectively two types of ROS (Scheme 5). The presence of catalase decomposing $\mathrm{H}_{2} \mathrm{O}_{2}$ should decrease the apparent photocatalytic activity if $\mathrm{H}_{2} \mathrm{O}_{2}$ were the key reactive oxygen species responsible for 1,2-dimethoxybenzene disappearance. On the other hand, superoxide dismutase, limiting the concentration of $\mathrm{O}_{2}{ }^{-}$and generating from this radical anion $\mathrm{H}_{2} \mathrm{O}_{2}$, should be detrimental for the photocatalytic activity if $\mathrm{O}_{2}{ }^{-}$were the main species responsible for the decrease in the 1,2-dimethoxybenzene concentration. 


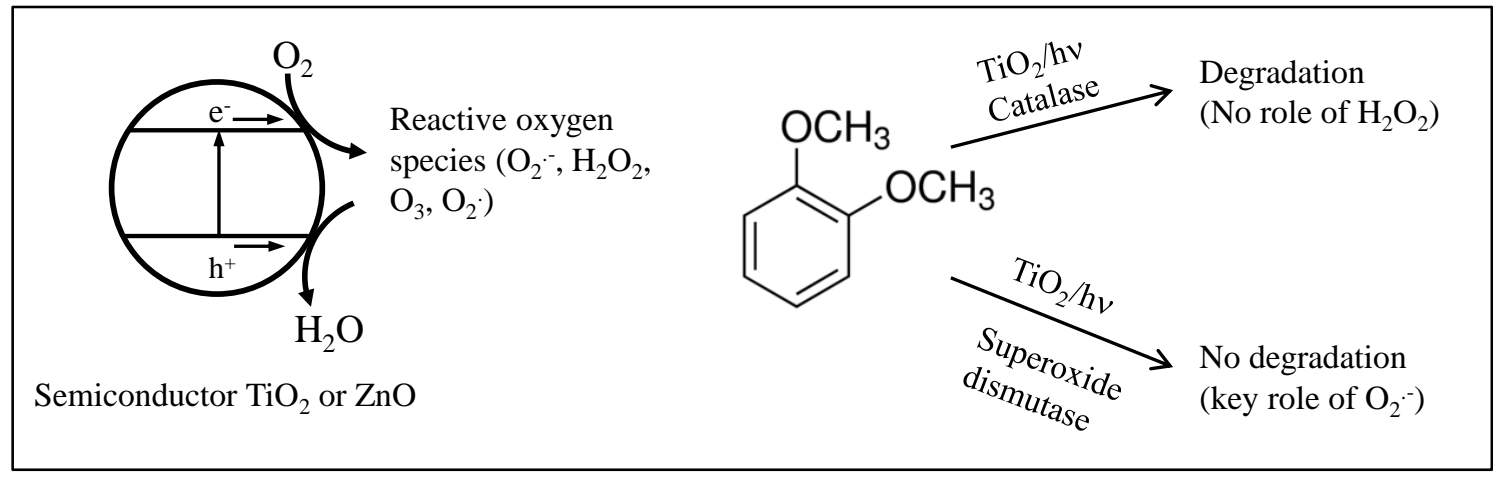

Scheme 5. Use of catalase and superoxide dismutase to intercept the photocatalytically generated ROS responsible for pollutant degradation.

Experimentally it was observed that the presence of catalase has no effect in the case of $\mathrm{ZnO}$ as photocatalyst and only moderate influence when $\mathrm{TiO}_{2}$ is employed as semiconductor. Furthermore, purposely addition of $\mathrm{H}_{2} \mathrm{O}_{2}$ has a negative effect on the photocatalysis by $\mathrm{ZnO}$ and it can be favorable and unfavorable in the photodegradation by $\mathrm{TiO}_{2}$ depending on the $\mathrm{H}_{2} \mathrm{O}_{2} / 1$,2-dimethoxybenzene ratio used in the experiment. These data indicate that $\mathrm{H}_{2} \mathrm{O}_{2}$ has no role when $\mathrm{ZnO}$ as photocatalyst and plays a secondary role in the case of $\mathrm{TiO}_{2}$ photocatalyst. In contrast, the presence of superoxide dismutase exerts a strong negative influence on the photocatalytic activity of both $\mathrm{TiO}_{2}$ and $\mathrm{ZnO}$, supporting the essential role of $\mathrm{O}_{2}{ }^{--}$as the active ROS promoting the disappearance of 1,2-dimethoxybenzene.

\section{Organic dyes as photosensitizers}

One of the simplest possibilities to promote the photochemical reduction of enzyme cofactors consists in the use of an organic dye dissolved in aqueous medium that in the presence of suitable electron donors acting as quenchers undergoes upon excitation a photoinduced electron transfer. A mediator molecule is generally needed to transfer electrons from the dye in its excited state to the enzyme cofactor. The use of dyes as light harversters to trigger the reduction of cofactors is quite general since electronically excited states are, simultaneously, much easier to be reduced by electron donation to the semi occupied HOMO orbital during the lifetime of the excited state than the ground state. Also it happens frequently that relevant excited states of photosensitizers are triplets since they have much longer lifetimes (typically a few microseconds) that makes electron transfer quenching more efficient than for singlets (typical lifetime of few nanoseconds). The reduced species of the organic dye generated in the electron transfer quenching of the excited state has enough red potential to be able to reduce of $\mathrm{NAD}^{+}$to $\mathrm{NADH}$ that is the cofactor of many reductases, although a mediator acting as relay is needed. In one of these studies, photocatalytically 
generated $\mathrm{NADH}$ obtained by $\mathrm{NAD}^{+}$reduction upon irradiation of organic dyes in the presence of amines and a $\mathrm{Rh}$ (III) organometallic complex $\left(\left[\mathrm{Cp} * \mathrm{Rh}(\mathrm{bpy}) \mathrm{H}_{2} \mathrm{O}\right]^{2+}, \mathrm{Cp}^{*}=\mathrm{C} 5 \mathrm{Me} 5, \mathrm{bpy}=2,2^{\prime}-\right.$ bipyridine) has been used to activate L-glutamate dehydrogenase that is able to convert $\alpha$ ketoglutarate to L-glutamate ${ }^{[11]}$. It was found that eosin Y (see structure in Scheme 6) can have a turnover frequency up to $1200 \mathrm{~h}^{-1}{ }^{[12]}$ that is much higher than other alternative photosensitizers such $\mathrm{Ru}(\mathrm{bpy})_{3}{ }^{2+}$ or pegylated chlorophylle or even inorganic $\mathrm{W}_{2} \mathrm{Fe}_{4} \mathrm{Ta}_{2} \mathrm{O}_{17}$. This high performance of eosin $Y$ is comparable to other xanthene dyes such as erythrosine $B$, phloxine $B$ and rose bengal ${ }^{[13]}$.<smiles>COC(=O)c1ccccc1-c1c2cc(Br)c(=O)c(Br)c-2oc2c(Br)c(O[N+]([O-])O)c(Br)cc12</smiles>

Scheme 6. Molecular structure of eosin Y.

This superior performance of eosin $\mathrm{Y}$ in this photobiocatalytic system was proposed to derive from precomplexation in the ground state of eosin $\mathrm{Y}$ and organometallic $\mathrm{Rh}$ complex leading to an efficient electron transfer between the dye in the excited state and the mediator ${ }^{[14]}$. The photobiocatalytic activity of eosin $\mathrm{Y}$, mediator system for the regeneration of $\mathrm{NAD}^{+}$in the visible light can be further enhanced by attaching these dyes molecules near $\mathrm{Au}$ nanoparticles (NPs) supported on a substrate. The multicomponent system is assembled using polydopamine, a polypeptide with high adhesive properties reminiscent to mussel proteins. Polydopamine is suppose to play three roles, namely, formation of Au NP by spontaneous reduction of $\mathrm{Au}^{3+}$ salts, embedding the dye near the surface of Au NP, and adhering the NP and dye on a slide glass. In this way, excitation of eosin $Y$ with photogeneration of electrons becomes much more efficient due to the plasmon resonance effect caused by the proximity to the Au NP surface (Scheme 7). 


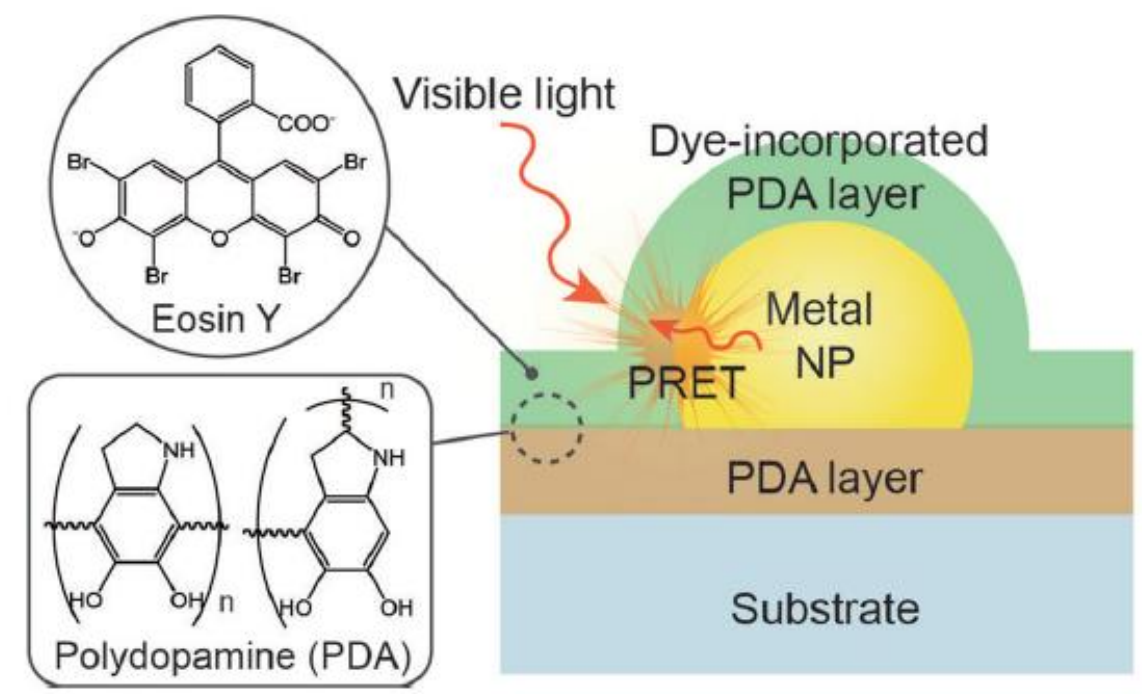

Scheme 7. Illustration of plasmonic nanohybrid for light harvesting. Polydopamine (PDA) coating enables formation of core-shell nanostructures integrated with metal NPs and dye photosensitizers, irrespective of the material type and morphology of substrates. (Figure taken with permission from ref ${ }^{[14]}$ ).

The ability of eosin $Y$ in combination of triethanolamine (TEOA) as electron donor and $\left\{\mathrm{Cp} * \mathrm{Rh}(\mathrm{bpy}) \mathrm{H}_{2} \mathrm{O}\right\}^{2+}$ as mediator to regenerate $\mathrm{NADP}^{+}$can be applicable to many enzymes using this cofactor ${ }^{[12]}$. Specifically P450 monoxygenase can operate with NADPH as cofactor producing the photobiocatalytic dealkylation of 7-ethoxycoumarin to 7-hydroxycoumarin. The operation of the enzymatic dealkylation can be simply followed by monitoring the fluorescence growth caused by the formation of 7-hydroxycoumarin, since the ethoxylated precursor is a non-fluorescent molecule (Scheme 8). 


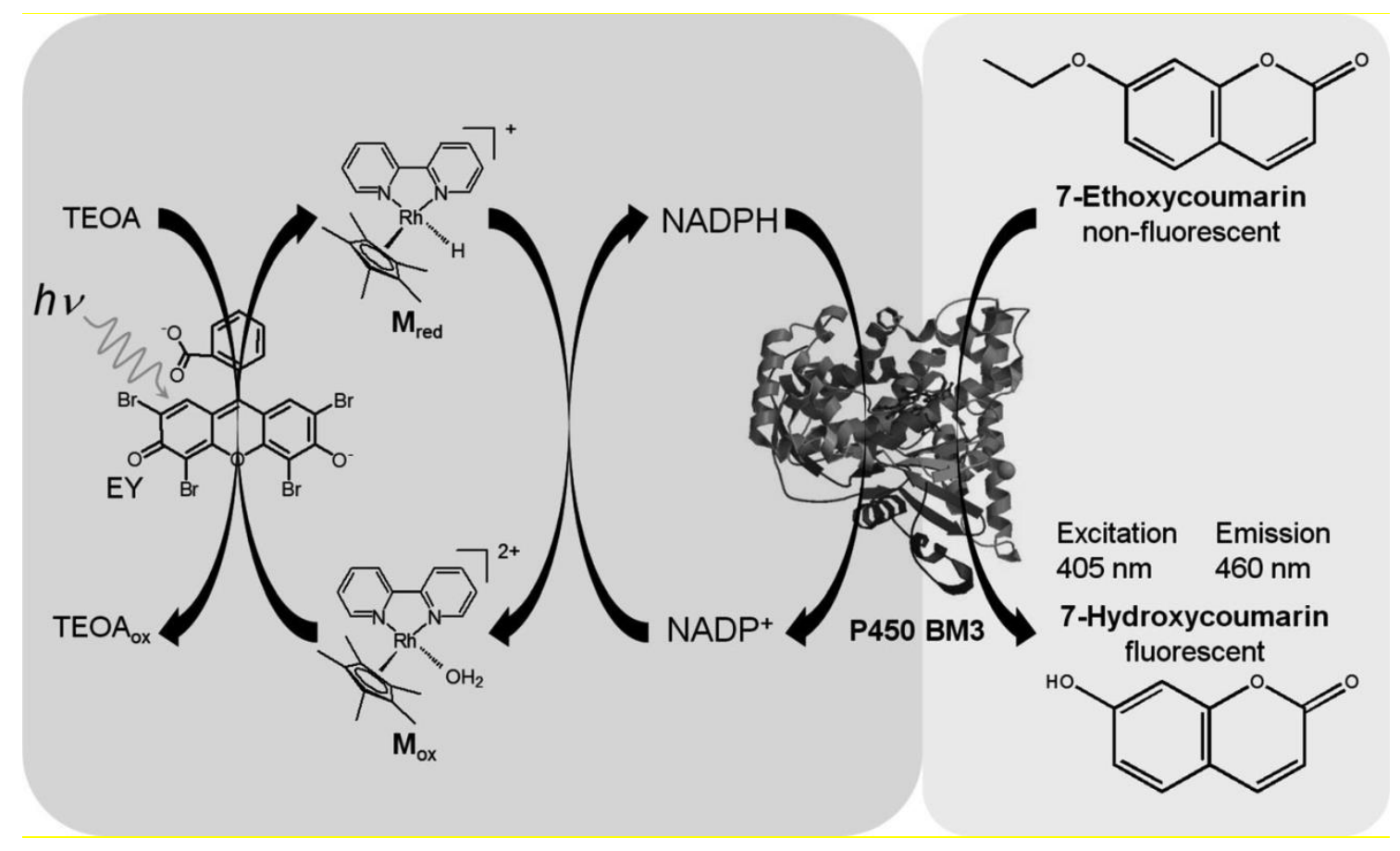

Scheme 8. Visible light-driven O-dealkylation by P450 BM3 coupled with NADPH photoregeneration. The catalytic turnover of P450 is achieved by photochemical regeneration of NADPH. (Figure taken with permission from ref ${ }^{[12]}$ ).

On the other hand, eosin $\mathrm{Y}$ in combination of Rh mediator and an electron donor can reduce efficiently analogs of $\mathrm{NAD}^{+}$with higher reduction potential such as 3-acetyl and 3carboxaldehyde pyridine adenine dinucleotide that can serve as an alternative to $\mathrm{NAD}^{+}$as enzymatic cofactor, for instance, for glutamate dehydrogenase (GDH). ${ }^{[15,16]}$

Other organic dyes that have been also employed as photosensitizers for the photochemical regeneration of NADH have been $\mathrm{Zn}$ porphyrins and proflavine ${ }^{[17,18]}$.

\section{Graphene oxide in photobiocatalysis}

Although metal oxides and chalcogenides have been by far the most studied photocatalysts due to their well-known semiconducting properties, ${ }^{[19-22]}$ there is an increasing interest in exploiting and developing photocarbocatalysts. ${ }^{[23-26]}$ Photocarbocatalysis refers to the use of metal-free carbonaceous materials as photocatalysts and is aimed at replacing costly and critical metals using biomass as sustainable from renewable resources. Since the discovery of fullerenes, a large family of carbon nanoforms with remarkable photochemical properties has become increasingly available. Among the many different properties of carbon allotropes, one that has attracted considerable attention refers to their ability to absorb light and participate in photoinduced electron transfer reactions ${ }^{[27-29]}$. Since charge separation upon light excitation 
is the general process that converts light into chemical energy, allowing to perform oxidations (in the positive hole) and reductions (in the negative site), the use of carbon nanoforms can expand the toolbox of materials to transform light into chemicals.

For instance, the remarkable electron acceptor ability of $\mathrm{C}_{60}$, being able to accept at moderate reduction potential up to 6 electrons, has been exploited in the preparation of dyads and triads in which covalent attachment of fullerene units accepting electrons enhance charge separation and at the same time increases the lifetime of these transients. ${ }^{[30-33]}$ Later, carbon nanotubes (CNTs) became available, representing a transition from molecular species (fulleroids) to materials. Also, CNTs have been widely used for photon induced electron transfer ${ }^{[34]}$ and optoelectronic applications, including photovoltaic cells. ${ }^{[35-38]}$ More recently, graphenes have been used as semiconductors. ${ }^{[39]}$ While ideal, defect-free graphene is considered as zero band gap semiconductor, in which the conduction band bottom and the valence band top have the same energy, the presence of defects, dopant elements or oxygen functionalities converts graphene from a conductor to a semiconductor material. ${ }^{[40-42]}$

The most studied graphene-based semiconductor is graphene oxide (GO), obtained by deep chemical oxidation of graphite and subsequent exfoliation of the graphite oxide material ${ }^{[43]}$. GO as a semiconductor has many advantages, derived from easy and reliable preparation and large availability from affordable carbon materials, large surface area, the possibility to reach high concentration in water and other solvents, and notable photocatalytic activity. To put into context the interest of $\mathrm{GO}$ as semiconductor it has to be considered that there are limited resources of metals and, for the sake of sustainability, it is very convenient to substitute metalbased materials for carbon-based materials. Apart from economic and environmental considerations, also from a chemical point of view, GO offers the possibility to apply concepts and procedures from organic chemistry to modify and functionalize these materials, while modification of inorganic semiconductors has been found much more problematic.

In this context, GO and CNTs form strong association complexes with many aromatic organic molecules due to the $\pi-\pi$ stacking between orbitals of the molecules with the extended $\pi$ system of the graphene semiconductor. This type of association can be used for the assembly of organic chromophores, particularly those having flat units such as porphyrins and phthalocyanines, to introduce light harvesters centers on a carbon semiconductor. A realization of this idea has been reported by Choudhury and coworkers ${ }^{[44]}$ to develop a photocatalytic system able to effect the $\mathrm{NAD}^{+}$reduction with visible light (Scheme 9). As photosensitizer a multianthroquinone-substituted porphyrin was used that assemblies on a graphene sheet. In this system, graphene plays the role of co-mediator accepting several electrons from the substituted porphyrin, transferring them to $\mathrm{NADP}^{+}$cofactor in an efficient 
way, mimicking the operation PSI system with an artificial system. It should be noted, however, that GO does not avoid the need of a Rh cyclopentadienyl complex as electron relay (Scheme 9). The photobiocatalytic system is complete by using an alcohol dehydrogenase from Lactobacillus kefir (LKADH) as enzyme to effect the stereoselective reduction of acetophenone to the corresponding chiral 1-arylethanol with high enantiomeric excess.

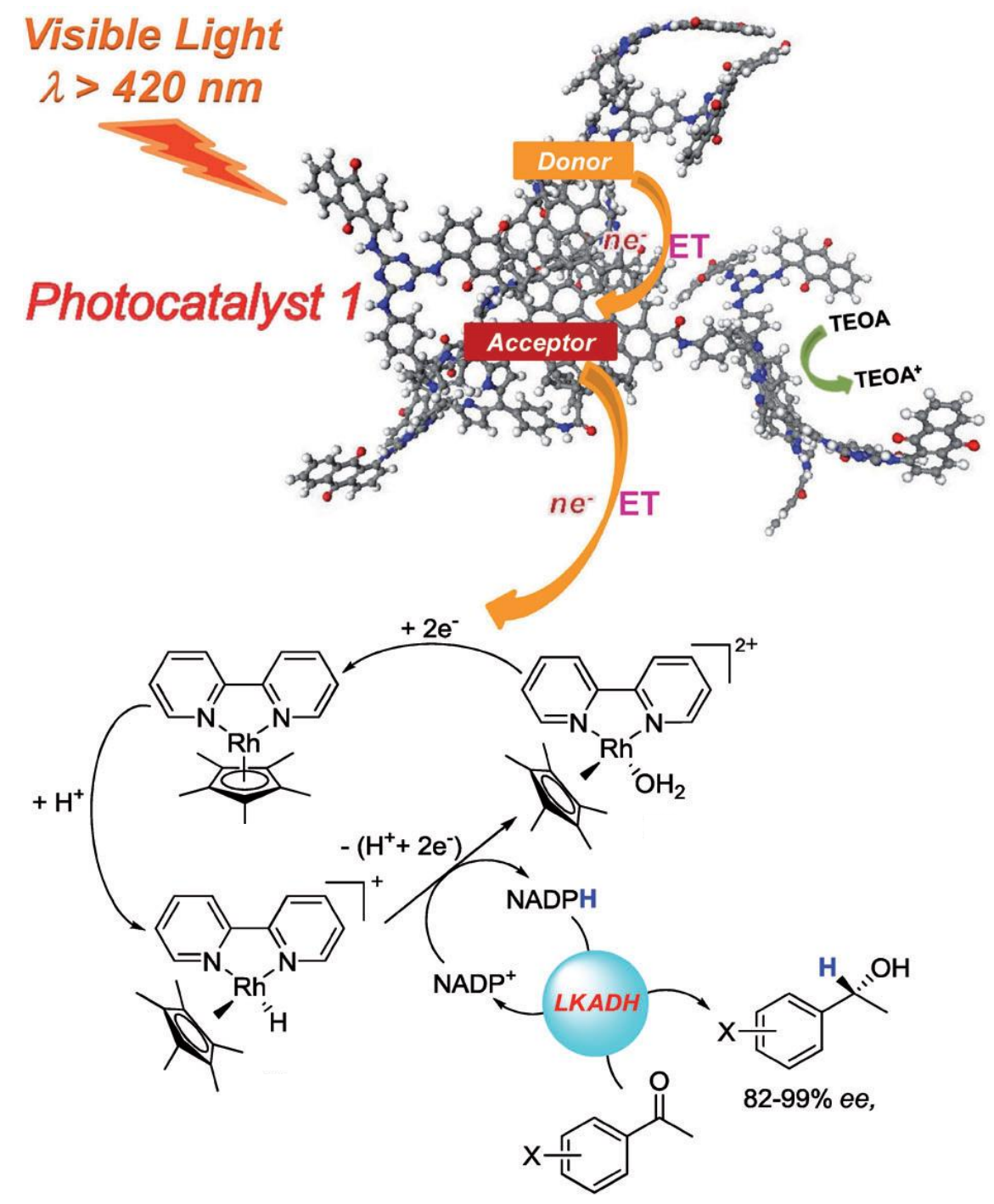

Scheme 9. GO as component of a photobiocatalytic system based on multianthroquinone porphyrin as light harvester, promoting the reduction of $\mathrm{NADP}^{+}$to NADPH. LKADH: alcohol dehydrogenase from Lactobacillus kefir. (Adapted with permission from ref ${ }^{[44]}$ ).

Considering the large current interest in carbon-based photocatalyst and the potential that these materials offer to interact with enzymes, there is no doubt that GO and related graphene semiconductors will be used to develop more complex and efficient photobiocatalytic systems 
making use of the adequate morphology and large surface area offered by graphene and that the use of graphene in combination with enzymes will grow in the near future.

Inorganic photobiocatalytic systems not based on $\mathrm{TiO}_{2}$.

Hydrogen-terminated silicon nanowires (NWs) have found to act as photobiocatalyst for $\mathrm{NADH}$ generation from NAD ${ }^{+}$using TEOA as sacrificial electron donor and organometallic Rh complex as mediator. The photocatalytic system generating NADH can be coupled with the enzymatic GDH that performs the formation of L-glutamate from $\alpha$-ketoglutarate. Comparison with similar silicon nanowires lacking $\mathrm{H}$ termination according to FTIR spectroscopy shows that this surface modification is crucial to observe photobiocatalytic activity since if $\mathrm{H}$ is removed completely from Si NWs by thermal treatment, then, no photocatalytic activity is observed. This requirement of surface modification has been rationalized assuming that photoinduced charge separation in Si NWs only takes place when the silicon surface is hydrogenated.

In a further development of Si NWs as photobiocatalyst, these materials, conveniently modified by deposition of Pt NPs on the surface, were used as photoanodes for the Rh mediated NADH regeneration coupled with L-glutamate dehydrogenase ${ }^{[45]}$ (Scheme 10).

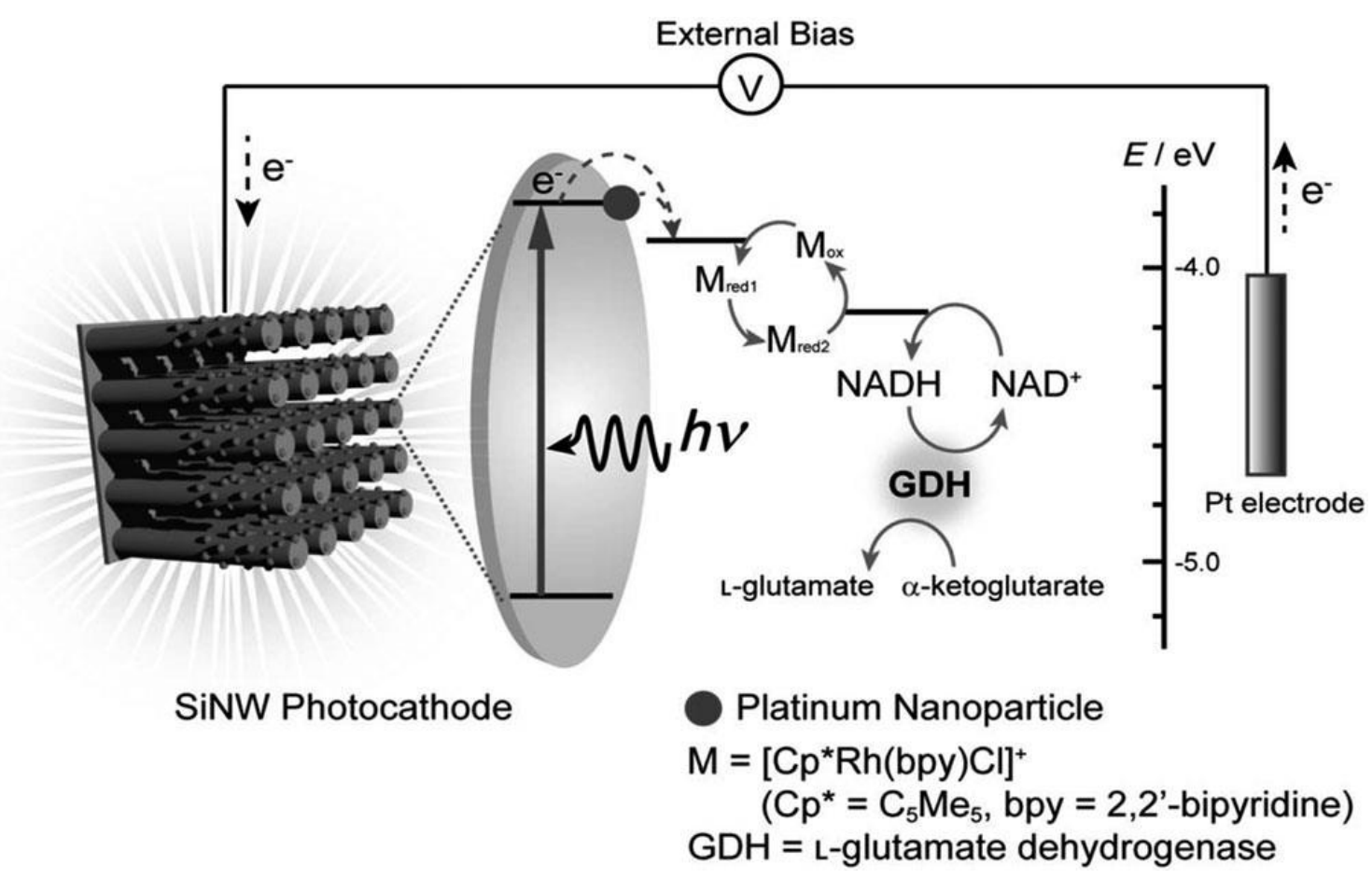

Scheme 10. Pictorial illustration of the photo-electroenzymatic reaction using a silicon nanowire (Si NW) photocathode. Photons absorbed by Si NWs generate excited electrons, 
which drift to the electrode/solution interface and reduce the mediator (M). NADH regeneration occurs triggered by photoinduced electron transfer. Finally, the regenerated $\mathrm{NADH}$ is used to convert $\alpha$-ketoglutarate to L-glutamate using GDH. (Figure taken with permission from ref ${ }^{[46]}$ ).

$\mathrm{W}_{2} \mathrm{Fe}_{4} \mathrm{Ta}_{2} \mathrm{O}_{17}$, obtained by solid state synthesis and having XRD patterns alike in a large extend to ferric tungstate $\left(\mathrm{Fe}_{2} \mathrm{WO}_{6}\right)$ with some additional peaks matching tantalum tungsten oxide is able to act as a photocatalyst under visible light irradiation for the $\mathrm{NAD}^{+}$reduction by EDTA as sacrificial electron donor in the presence of organometallic Rh mediator. The system can be coupled with glutamate dehydrogenase giving rise to the formation of L-glutamate by reduction of $\alpha$-ketoglutarate. The photoelectrobiocatalytic system has the advantage of not requiring sacrificial amine to reduce $\mathrm{NAD}^{+}$although it requires the application of a bias voltage of $-0.8 \mathrm{~V}$ in order to promote the photoelectrochemical $\mathrm{NAD}^{+}$reduction.

$\mathrm{Cd}$ quantum dots having small crystal size (average $5 \mathrm{~nm}$ ), particularly, $\mathrm{CdTe}$, in the presence of cyclopentadienyl Rh complex as mediator have been found to be highly efficient photocatalysts for the visible light $(\lambda<400 \mathrm{~nm}) \mathrm{NAD}^{+}$reduction in aqueous solution of TEOA ${ }^{[47]}$. It was found that the concentration of Rh mediator is a key factor to ensure an optimal vectorial electron transfer from excited quantum dot to $\mathrm{NAD}^{+}$that is about six orders of magnitude lower when the Rh mediator is absent. Under the best experimental conditions most of the photogenerated excited electrons from quantum dots are transferred to $\mathrm{NAD}^{+}$ through the intermediacy of Rh complex. In contrast, analogous $\mathrm{Cd}$ chalcogenides samples of micrometric particle size do not exhibit any photocatalytic activity, thus, revealing the importance of using photocatalysts of nanometric dimensions. CdS quantum dots and the GDH can be deposited on a microfluidic reactor having a zone illuminated with visible light in where the quantum dots are located and another non illuminated zone where the enzymatic process takes place consuming the photogenerated NADH ${ }^{[48]}$. Additionally, $\mathrm{CdS}$ quantum dots can be deposited on silica beads of uniform submicrometric particle size ${ }^{[49]}$. By means of $\left\{\mathrm{Cp} * \mathrm{Rh}(\mathrm{bpy}) \mathrm{H}_{2} \mathrm{O}\right\}^{2+}$ mediator, silica beads coated with $\mathrm{CdS}$ are able to regenerate using visible light NADH that can act as cofactor in the enzymatic synthesis of L-glutamate by GDH. It was found that agglomeration of $\mathrm{CdS}$ or an increase in the $\mathrm{CdS}$ average particle size are detrimental for the performance of this photobiocatalytic system.

Spatial structuring of photobiocatalytic systems. 
One strategy that has been used to enhance the photocatalytic activity of semiconductors has been the control of the morphology and structuring the particles from the subnanometric to the submillimetric length scale. ${ }^{[50]}$ Thus, for instance, reduction of particle size to a few nanometers can enhance the photocatalytic activity by introducing quantum chemical effects and confinement of electrons in a small spherical box. ${ }^{[51-53]}$ On the other hand, nanotubes and nanorods can also enhance the photocatalytic activity of semiconductors, particularly by allowing fast electron migration along the long axis direction of the nanorod. All these physical strategies based on control of the semiconductor morphology and spatial structuring of various components have been applied frequently in the case of $\mathrm{TiO}_{2}{ }^{[50]}$ One of the best examples is the use as semiconductor of $\mathrm{TiO}_{2}$ nanotube arrays prepared by anodic oxidation at high voltages and current intensities of thin Ti metal foils in a fluoride medium. ${ }^{[54-57]}$ Physical studies have shown that in these nanotube arrays there is a preferential electron migration in the direction of the nanotubes. ${ }^{[58-60]}$ Some of these systems, as the one reported by Grimes in where the $\mathrm{TiO}_{2}$ array is doped with $\mathrm{N}$ to increase the visible light absorption and coated with $\mathrm{Pt}$ and $\mathrm{Cu}$ metals, ${ }^{[61]}$ is among the most efficient systems to promote the photocatalytic $\mathrm{CO}_{2}$ reduction by water using solar light. ${ }^{[62]}$

Not surprisingly, the concept of $\mathrm{TiO}_{2}$ structuring as nanotubes has also been applied for the development of a photobiocatalyst. ${ }^{[63]}$ Specifically, CdS quantum dots have been deposited on $\mathrm{TiO}_{2}$ nanotubes to develop a heterojunction nanostructure for photoelectrocatalytic $\mathrm{NAD}^{+}$ reduction using a mediator. The narrow band gap CdS semiconductor absorbs visible light and injects one electron into the conduction band of $\mathrm{TiO}_{2}$ that due to its morphology allows fast migration of the electron through the nanotube over long distances, favoring charge separation. These electrons are finally transferred to $\mathrm{NAD}^{+}$through a mediator. Scheme 11 illustrates the concept of $\mathrm{CdS}-\mathrm{TiO}_{2}$ nanotube heterojunction to perform $\mathrm{NAD}^{+}$reduction.

It is clear that structuring of the photocatlyst allows developing more elaborate systems that can have higher similarities with the natural photosynthetic centers and this methodology should be further developed in the future. 


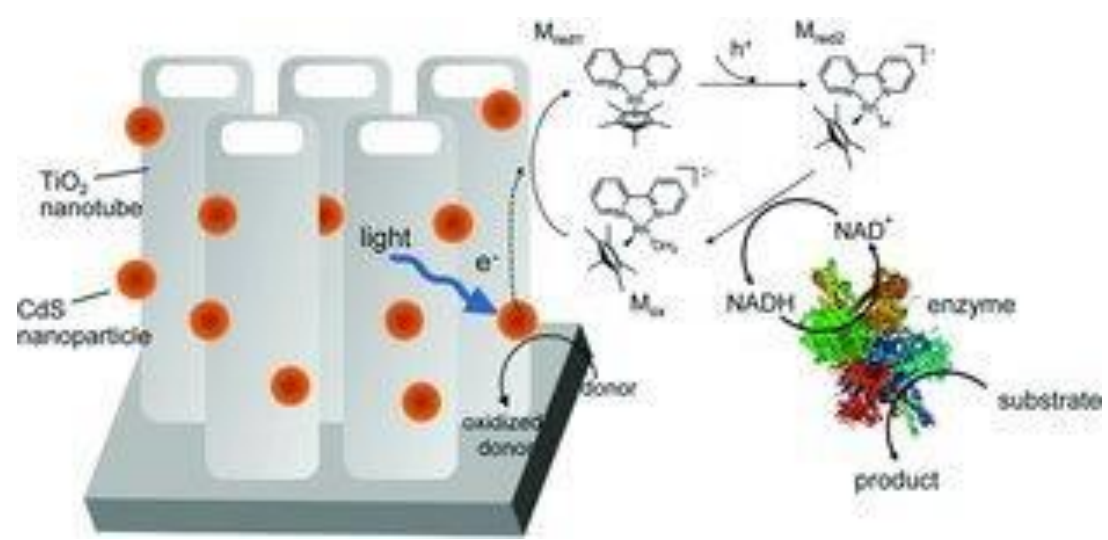

Scheme 11. CdS quantum dot-sensitized $\mathrm{TiO}_{2}$ nanotube arrays for photocatalytic reduction of $\mathrm{NAD}^{+}$allowing the operation of a coupled enzymatic system. (Taken with permission from ref $\left.^{[63]}\right)$.

\section{Photobiocatalysts mimicking PSII}

Natural photosystem PSII is characterized by evolving oxygen from water and transferring electrons to electron relays. Water is, however, a poor electron donor and in many examples amines are used as sacrificial electron donors even if the photobiocatalytic process is carried out in water and sacrificial agents would not be strictly necessary. For the sake of atom economy, it would be of interest to develop artificial photobiocatalytic systems that can be able to extract electrons from water mimicking the process occurring in the PSII centers of green plants. In this section we will describe those photobiocatalytic systems that in a certain way have been reported to perform similar processes.

Upon excitation with photons of energy larger than the bandgap, a semiconductor undergoes charge separation by the creation of holes in the valence band and electrons in the conduction band. However, in order to increase the efficiency in the photocatalytic processes, it is convenient to attach to the semiconductor some other centers that should provide a fast management of electrons or holes. These centers are generally denoted as "co-catalysts", since their presence enhances considerably the efficiency of the photocatalytic processes, frequently two orders of magnitude. ${ }^{[64-66]}$ Noble metals such as Pt or Au are the most general catalytic centers to store electrons from $\mathrm{TiO}_{2}$ conduction band promoting efficiently their transfer to substrates and, therefore, these noble metal NPs accelerate reduction processes. In a similar way, transition metal oxides such as $\mathrm{IrO}_{2}, \mathrm{RuO}_{2}$ and $\mathrm{CoO}$ are cocatalysts to promote oxygen evolution from water. Further elaboration of co-catalysts can be inspired in the natural photosynthetic center.

In a pioneering work coupling photocatalysis with enzymes, Hollmann and Corma ${ }^{[67]}$ have combined the photocatalytic activity of Au nanoparticles (NPs) supported on $\mathrm{TiO}_{2}$ with the enzymatic activity of oxidoreductase by means of $\mathrm{FAD}^{+}$as mediator and cofactor to achieve the 
stereospecific hydrogenation of conjugated $\mathrm{C}=\mathrm{C}$ bonds of ketoisophorone (See Scheme 12). In previous work in the literature, ${ }^{[34]} \mathrm{Au} / \mathrm{TiO}_{2}$ has been found to be a highly efficient photocatalyst for hydrogen generation from water-methanol mixtures under sunlight irradiation and exhibiting photocatalytic response even under exclusive visible light irradiation. In the present photocatalytic system, methanol is absent and water becomes the only sacrificial electron donor present in the medium, generating oxygen in the process. Although the absence of methanol should reduce the efficiency of the hole quenching, and consequently the yield of electrons of $\mathrm{TiO}_{2}$ conduction band available for reduction of $\mathrm{FAD}^{+}$mediator, the exclusive use of water makes the system more alike to the enzymatic conditions in PSII, increasing the interest of the process. Electrons in the conduction band of $\mathrm{TiO}_{2}$ or on $\mathrm{Au} \mathrm{NPs}$ should reduce $\mathrm{FAD}^{+}$to the corresponding reduced form $\mathrm{FADH}_{2}$ that is the cofactor necessary to activate the oxidoreductase. The oxidoreductase in this study was obtained from E. Coli BL21 (DE3) that was transfected with a gene encoding the wanted enzyme ${ }^{[67]}$. After activation of the oxidoreductase with $\mathrm{FADH}_{2}$, the enzyme exhibits activity to convert ketoisophorone to the corresponding (R)-levodione. Scheme 12 depicts the components of the photobiocatalytic system and the enzymatic enantioselective reduction of the conjugated $\mathrm{C}=\mathrm{C}$ bond with water and light as reagents.

The influence of the amount of $\mathrm{Au} / \mathrm{TiO}_{2}$ and enzyme on the product yield shows that for a given operation condition once a certain amount of the two components is present in the system the reaction rate reaches a plateau without significant changes in the enantiomeric excess of the (R)-levodione. Kinetic studies have shown that the rate limiting step of the process is the photocatalytic regeneration of the flavin $\mathrm{FADH}_{2}$ due to the difficulty in achieving water oxidation. The presence of mediators acting as electron relays between the semiconductor and $\mathrm{FAD}^{+}$and/or the use of more efficient sacrificial donors could probably alleviate this bottleneck and could enhance even, further, the photocatalytic activity. To improve the activity of $\mathrm{Au} / \mathrm{TiO}_{2}, \mathrm{~V}$-doped $\mathrm{TiO}_{2}$ was used as photocatalyst showing higher activity than $\mathrm{Au} / \mathrm{TiO}_{2}$. Thus, it appears that this metal doped $\mathrm{TiO}_{2}$ could have promising photobiocatalytic activity under visible light. 


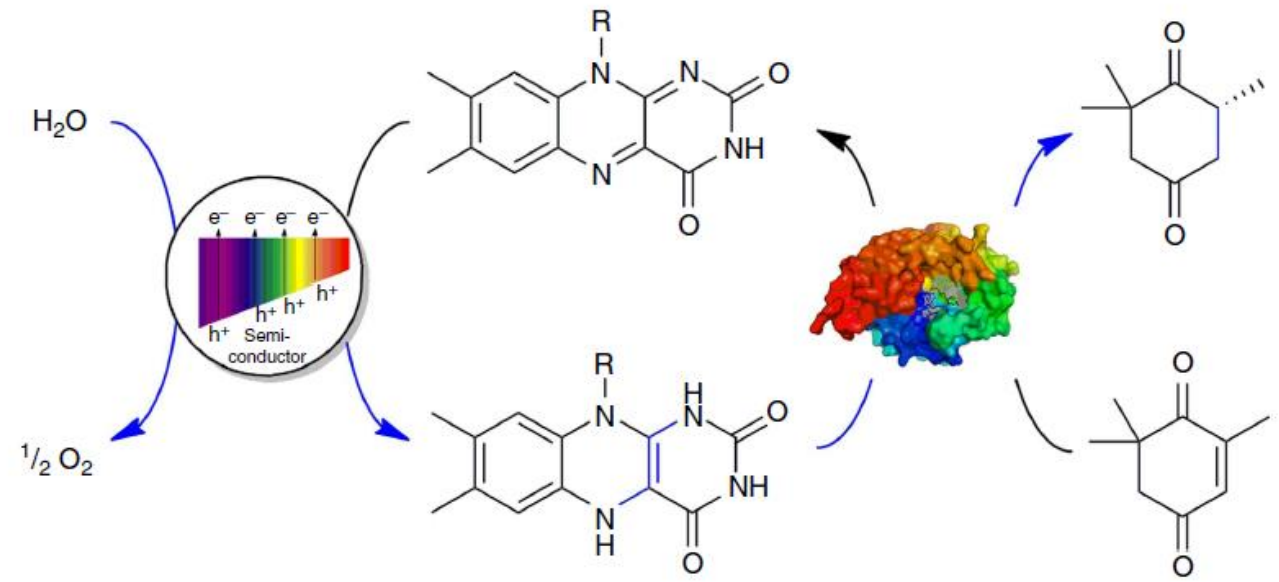

Scheme 12. Photobiocatalytic enantioselective reduction of ketoisophorone to (R)levodione by an oxidoreductase enzyme mediated by $\mathrm{FADH}_{2}$ using $\mathrm{Au} / \mathrm{TiO}_{2}$ as semiconductor and water as sacrificial electron donor. (Taken with permission from ref. ${ }^{[67]}$ ).

In a study that has as key point also the use of water as electron donor in the photobiocatalytic synthesis of L-glutamate from $\alpha$-ketoglutarate by enzymatic reduction promoted by GDH employing NADH as cofactor, Park and coworkers ${ }^{[68]}$ used a homogeneous, molecular photocatalytic system based on Ru(II) trisbipyridyl complex as light harvester, organometallic $\mathrm{Rh}$ as mediator and cobalt polyoxometalate as cocatalyst for hole scavenging from the Ru complex (Scheme 13). The key point of the system is to use two different cocatalysts namely the Rh complex and Co polyoxometalate for efficient management and quenching of the triplet excited states of $\mathrm{Ru}(\mathrm{bpy}){ }_{2}{ }^{3+}$ photosensitizer. In the previous sections we have already amply commented the convenience of using a mediator to transfer photogenerated electrons to $\mathrm{NAD}^{+}$in the form of hydride. Similarly, cobalt polyoxometalate is a good catalyst to generate oxygen from water with low overpotential, therefore, making unnecessary the use of alcohols or amines as sacrificial electron donors. In this way, the whole molecular photosystem is pumping electrons from water to the enzyme, generating oxygen in the process in a very similar way to the operation of natural photosynthetic centers in green plants. 


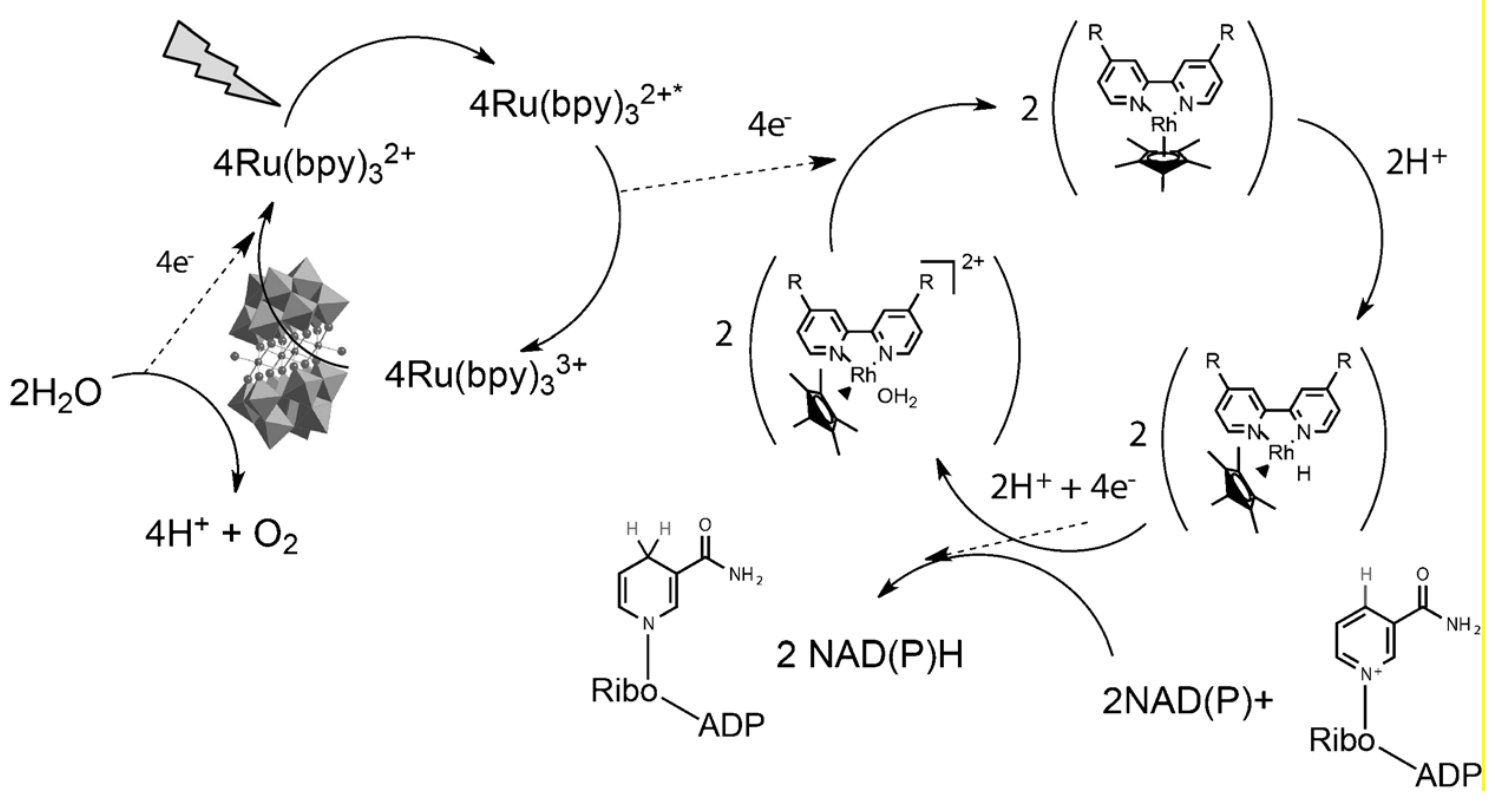

Scheme 13. Diagram showing the whole cycle for the photocatalytic regeneration of NAD(P)H cofactors using $\mathrm{H}_{2} \mathrm{O}$ as sacrificial electron donor and a cobalt polyoxometallate as cofactor. (Taken with permission from ref ${ }^{[68]}$ ).

One of the major targets in photocatalysis that should result in an increase in solar light photoresponse has been to expand the photocatalytic activity from the UV to the visible region. However, besides visible light sunlight reaching the Earth surface contains a large percentage (about $46 \%$ ) of near infrared (NIR) wavelengths that in general have insufficient energy to promote electronic transitions from HOMO-LUMO levels in dyes and semiconductors. It would be also important if this large proportion of NIR energy present in the sunlight could be used in photobiocatalysis. In one clever approach aimed at utilization of NIR wavelengths, Park and coworkers ${ }^{[69]}$ have prepared nanoparticles of $\mathrm{NaYF}_{4}$ that when codoped with $\mathrm{Yb} / \mathrm{Er}$ or $\mathrm{Yb} / \mathrm{Tm}$ (less efficient due to poor overlap of the emission with the Rose Bengal absorption) are able to perform an efficient up conversion in which NIR photons are transformed into visible photons. $\mathrm{NaY}(\mathrm{Yb}, \mathrm{Er}) \mathrm{F}_{4}$ were coated with silica ( $8 \mathrm{~nm}$ thickness) and functionalized with 3-aminopropyltrimethoxysilane to introduce positive charges on the surface for a strong electrostatic interaction with negatively charged Rose Bengal that will act as the light harvesting dye in the system. Scheme 14 summarizes the concept of NIR photon up conversion to green light, resulting in electronic excitation of Rose Bengal. In the presence of TEOA as hole quencher and a Rh complex as mediator, NIR photons promote the regeneration of $\mathrm{NADH}$ cofactor from $\mathrm{NAD}^{+}$and in the complete photobiocatalytic system L-glutamate is obtained from $\alpha$-ketoglutarate using GDH as enzyme. 


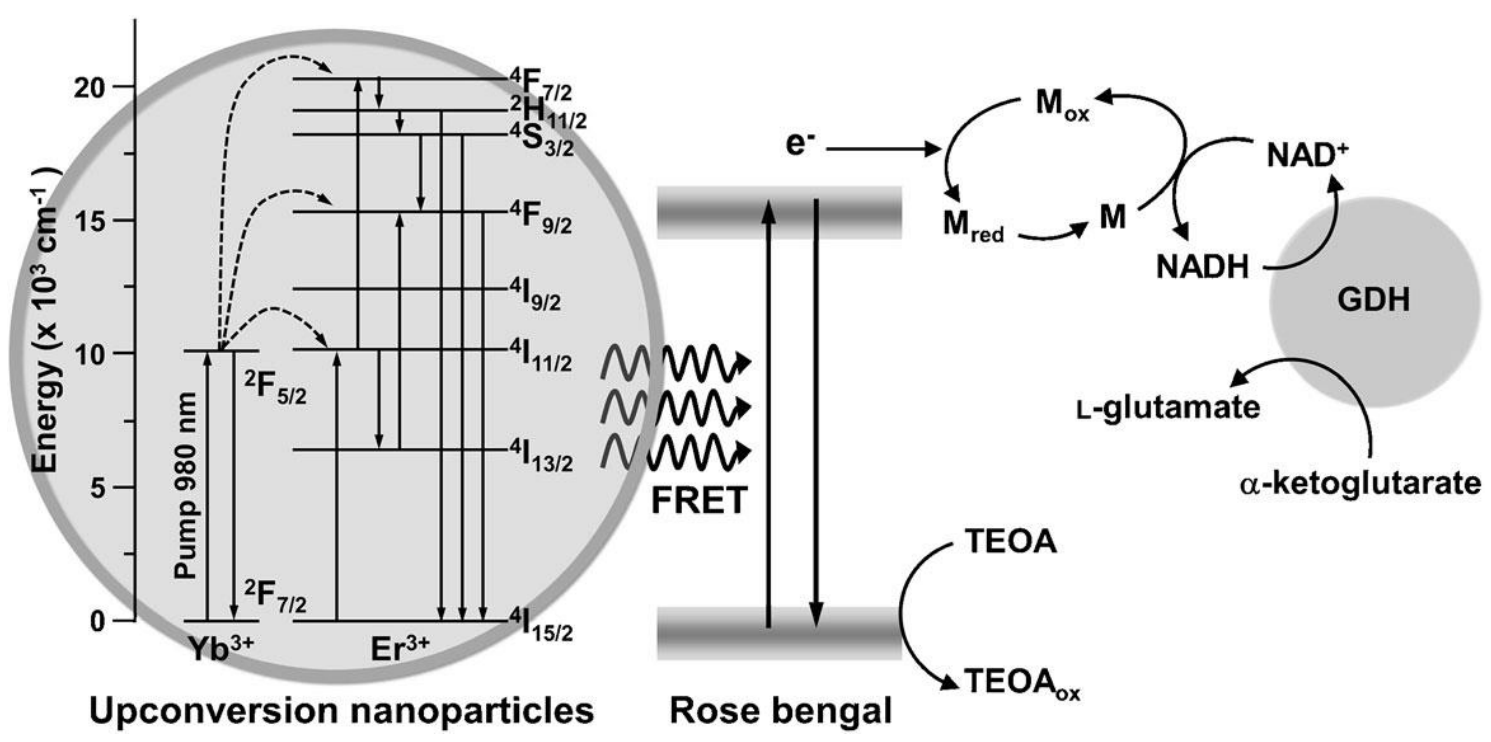

Scheme 14. Schematic diagram of NIR-light-driven biocatalytic artificial photosynthesis. (Taken with permission from ref ${ }^{[69]}$ ).

In natural PSII system there is a $\mathrm{CaMn}_{4} \mathrm{O}_{5}$ cluster that can be considered that is acting as cocatalyst of the photocatalytic center. These $\mathrm{CaMn}_{4} \mathrm{O}_{5}$ clusters are near a tyrosine and a histidine of the enzyme structure. It is proposed that the role of these amino acids is assistance of electron transfer by proton transfer. Inspired by the environment of natural oxygen evolving center, a benzimidazole-phenol ligand has been attached through carboxylate groups to the surface of $\mathrm{IrO}_{\mathrm{x}}$ nanoparticles to assist similarly the electron transfer from water to $\mathrm{IrO}_{2}$ by proton transfer from the organic linkers. ${ }^{[70]}$ It was found that the system consisting in $\mathrm{Ru}(\mathrm{bpy})_{3}{ }^{2+}$ (bpy: 4,4'-bipyridine) as light harvester, $\mathrm{TiO}_{2}$ as photocatalyst, $\mathrm{IrO}_{2}$ as oxygen evolution center increases the photocatalytic efficiency for $\mathrm{O}_{2}$ generation with a factor higher than 2 when the benzimidazole-phenol ligand is present. Scheme 15 illustrates the concept inspired in the natural oxygen evolution center to develop a photocatalytic system based on $\mathrm{TiO}_{2}$ exhibiting enhanced oxygen evolution. 


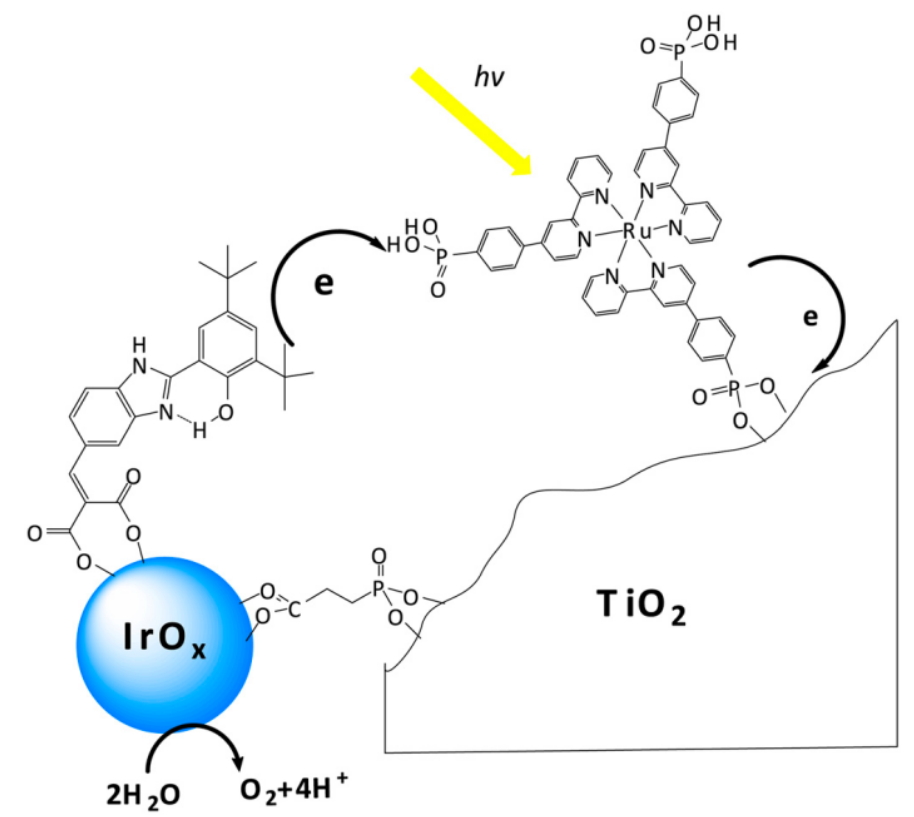

Scheme 15. Molecular arrangement of $\mathrm{IrO}_{2} \mathrm{NPs}$ modified by benzimidazole-phenol units to assist $\mathrm{H}^{+}$transfer and $\mathrm{Ru}(\mathrm{bpy})_{3}{ }^{2+}$ as light harvester in dye-sensitized $\mathrm{TiO}_{2}$. The drawing indicates the electron transfer processes occurring in the mediator-based, dye-sensitized $\mathrm{TiO}_{2}$. (Taken with permission from ref. ${ }^{[70]}$ ).

Natural photosynthetic centers PSI and PSII have each of them an independent light harvesting center spatially attached to the oxygen evolution center (PSII) or to NADP reductase through flavin as electron relay (PSI) (Scheme 1). The light harvesting center is characterized by an array of porphyrins that harvest photons and funnel all the collected energy in one direction towards the corresponding photocatalytic center. The key feature of the system is the spatial arrangement and ordering of the porphyrin array that are immobilized in the thylakoid membrane (Scheme 1). In an attempt to mimic this type of natural light harvesting centers, the capsid of the M13 virus has been used as platform to attach in an ordered manner porphyrin molecules at an appropriate distance on a linear configuration (Scheme 16). ${ }^{[71,72]}$ Apparently, the protein of the M13 virus contains in a regular and periodic way lysine amino acids that are able to bind strongly to the porphyrin through their free primary amino groups. The regularity of the arrangement of the porphyrin units is proposed to be responsible for the high efficiency of the porphyrin/M13 assembly combined with $\mathrm{IrO}_{2}$ nanoparticles for water oxidation, reaching TON for oxygen evolution of about 800 . 


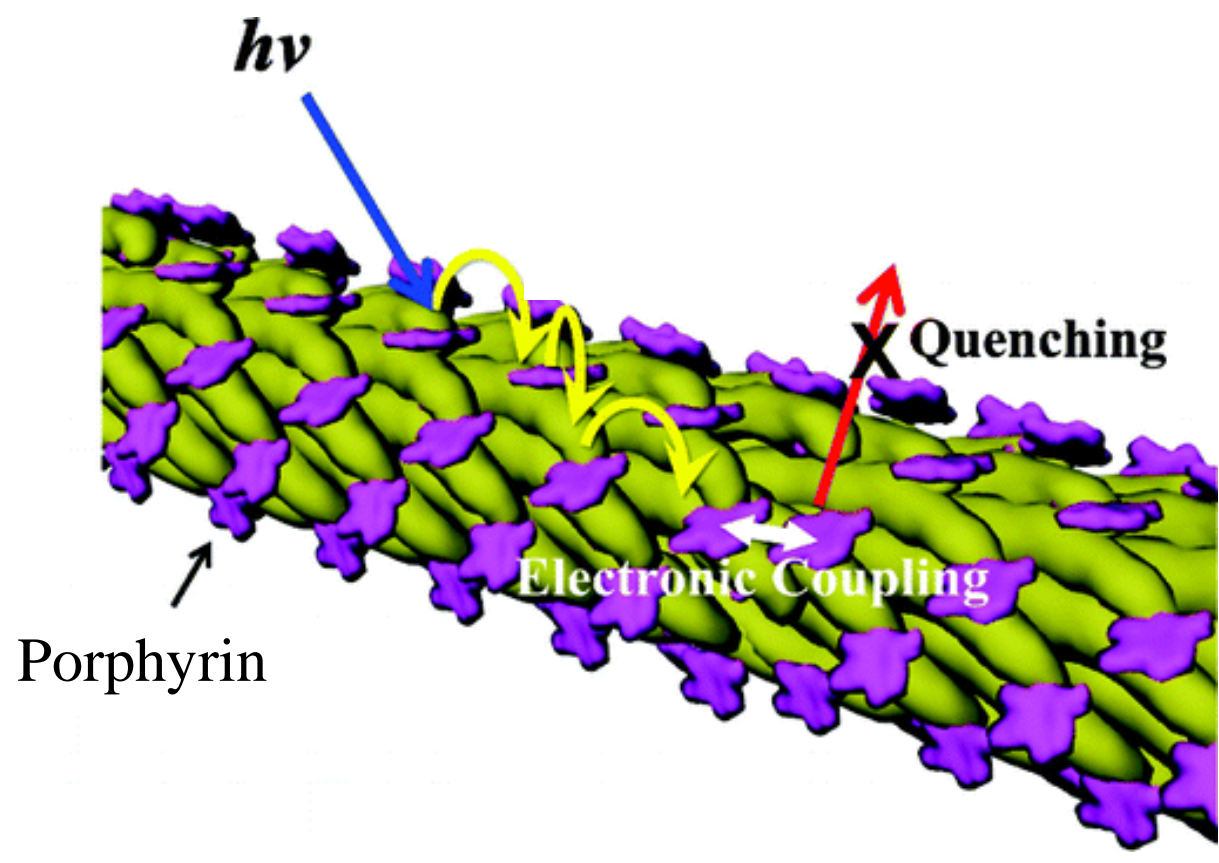

Scheme 16. Arrangement of porphyrin complexes onto a one-dimensional light-harvesting antenna using M13 virus capsid as scaffold. (Figure taken with permission from ref ${ }^{[72]}$ ).

A dipeptide of phenylalanine, functionalized at the free amino group by a Fmoc-FF and having free carboxylate groups self-assembled in water leading to hydrogels. These hydrogels can incorporate, mainly throw electrostatic interactions between the negative carboxylate group and the positive pyridinium units with meso-tetra(4-pyridyl) porphyrin and the whole having iridium oxide as oxygen evolution center can act as solar light driven photocatalyst for oxygen generation from water using $\mathrm{S}_{2} \mathrm{O}_{8}{ }^{2-}$ as electron acceptor ${ }^{[73]}$. In principle, considering the high efficiency for $\mathrm{O}_{2}$ evolution from water, this system using a mediator would be equally promising as photobiocatalyst using water as electron donor. ${ }^{[73]}$ As expected peptide nanotubes spontaneously formed by self-assembly of diphenylalanine and containing mesotetra(4-pyridyl) porphyrin as light harvesting dye and Pt nanoparticles as cocatalysts for conduction band electrons management can, in the presence of organometallic Rh as mediator, promote the reduction of $\mathrm{NAD}^{+}$to $\mathrm{NADH}$ using visible light, much more efficiently than the individual components of this system, other combinations or alternatives photocatalysts such as $\mathrm{Cd}$ chalcogenides ${ }^{[74]}$. $\mathrm{IrO}_{2}$ as cocatalyst of $\mathrm{TiO}_{2}$ nanofibers synthesized by electrospinning (about $200 \mathrm{~nm}$ diameter, long aspect ratio) have also shown high efficiency for $\mathrm{O}_{2}$ generation ${ }^{[75]}$. Other efficient photocatalytic system for $\mathrm{O}_{2}$ evolution consists in the assembly of polydopamine as electron gate, carbon nanotubes as electron acceptor, $\mathrm{Ru}(\mathrm{bpy})_{3}{ }^{2+}$ as light harvester using cobalt phosphate as hole scavenger and cocatalyst for $\mathrm{O}_{2}$ evolution ${ }^{[76]}$. This combination of Ru complex as light harvester and cocatalysts and electron gates could be 
also of interest in those photobiocatalytic systems in which water should be the sacrificial electron donor. Other examples are $\mathrm{RuO}_{2}-\mathrm{CO}_{3} \mathrm{O}_{4}$ core shell $1 \mathrm{D}$ nanofibres as oxygen evolution catalyst ${ }^{[77]}$.

In the natural photosynthetic systems, chlorophylls having porphyrinic macrocycle are the light harvesters centers. In a very interesting work porphyrin molecules have been incorporated into the porous matrix of lignocelluloses ${ }^{[78]}$. While cellulose provides porosity and capacity to adsorb porphyrin, lignin plays apparently an additional active role in the photocatalytic process by accepting electrons from porphyrin excited state and favouring the coupling of electron transfer with protons transfer by means of the guaiacyl and hydroquinone units present in lignin (Scheme 17). In a certain way the role of lignocellulose resembles that of the quinones present in the cytochrome complex acting as electron relays from PSII to PSI in the natural photosynthetic system. Accordingly, it was observed that when the percentage of lignin in the lignocellulosic matrix increases, the efficiency of porphyrins as photosensitizers to promote the photocatalytic reduction of $\mathrm{NADP}^{+}$also increases.

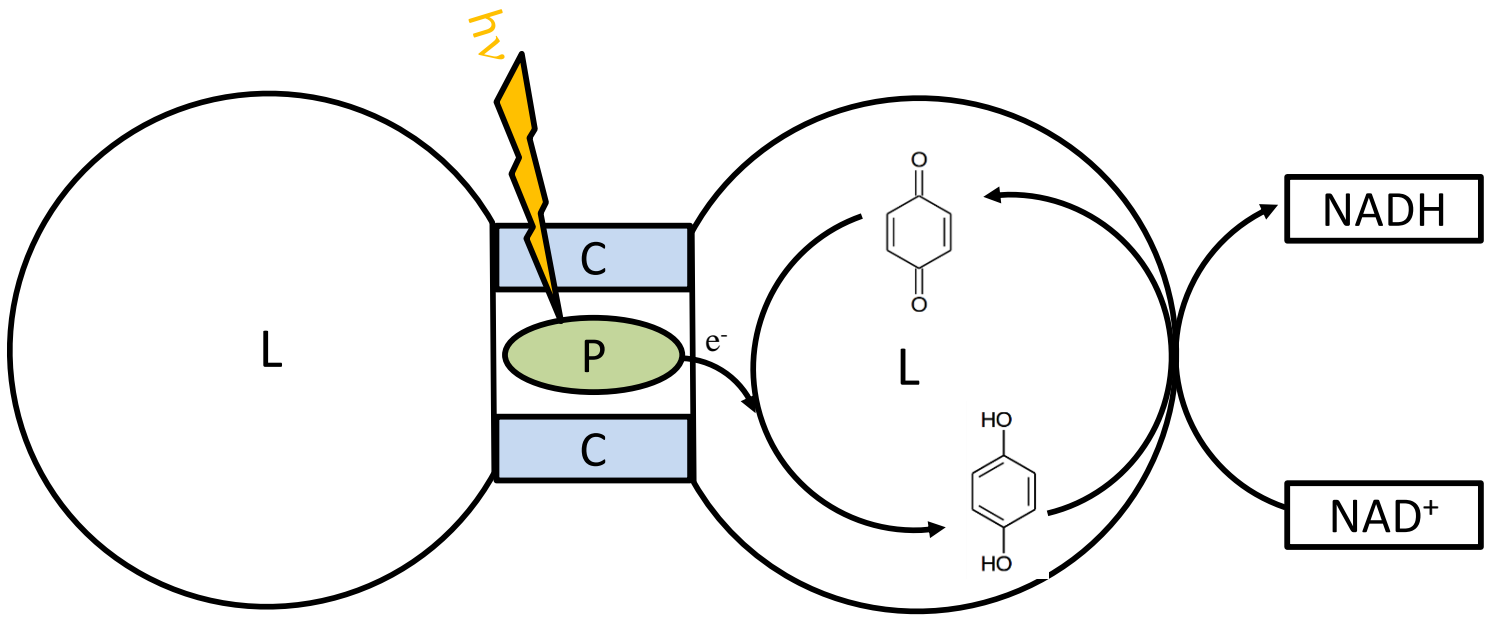

Scheme 17. Photocatalytic activity of porphyrin (P) embedded in the cellulose (C) part of the lignocellulose. The lignin part $(L)$ contains hydroquinone/quinone pairs that act as efficient relays in the reduction of $\mathrm{NAD}^{+}$to $\mathrm{NADH}$.

\section{Photobiocatalysis without mediators}

One important point in photobiocatalysis is to address the possibility to avoid the use of mediators and even cofactors by transferring directly electrons from the semiconductor surface to the active site of the enzyme. Since the field of photobiocatalysis is now emerging and the current systems are still far from achieving optimal performance, future work should address this important issue trying to solve in an efficient way which are the best mediators to 
shuttle electrons from the photocatalyst to the cofactor and if they are convenient from the point of view of efficiency of the process. The possibility to inject directly electrons from the semiconductor to the active center of some enzymes should be determined. Understanding of the interplay between mediator and cofactor and the possibility to activate directly the enzyme by the semiconductor can be also important to expand the type of enzymes and processes that can be promoted by photobiocatalysis.

At the present, most of the mediators reported so far to transfer the electrons from the semiconductor to the cofactor or the enzymatic system contain noble metal either as coordination complexes or organometallic complexes. It would be of interest to develop alternative mediators using affordable first-raw transition metals, such as complexes containing $\mathrm{Fe}, \mathrm{Co}, \mathrm{Mn}$ or other abundant metals. Even purely organic mediators with quinonehydroquinone structure or other organic redox pairs should also be explored for the different types of photobiocatalytic processes.

The possibility to activate directly the active site of the enzyme by the semiconductor in the absence of cofactors or cofactor and mediator will simplify considerably the operation of photobiocatalytic systems. Most probably this approach requires some kind of pre-association between the semiconductor and the enzyme, in such a way that a channel through which electrons can travel throughout the enzyme to reach the redox active center become attached close to the facets and planes of the semiconductor on which electrons are preferentially located, if this happens to be the case. For instance, recent progress in the synthesis of $\mathrm{TiO}_{2}$ using $\mathrm{F}^{-}$ions to control the growth and morphology of $\mathrm{TiO}_{2}$ crystallites has shown that it is possible to obtain truncated octahedral particles with various possible ratios between the areas of the 100 vs. 111 planes by controlling the synthesis conditions and more specifically the $\mathrm{F}^{-}$concentration. ${ }^{[79]}$ By observing the location of NPs formed by photocatalytic reduction ( $\mathrm{Pt} N \mathrm{Ns}$ from $\mathrm{Pt}^{\mathrm{IV}}$ ) or oxidation $\left(\mathrm{PbO}_{2} \mathrm{NPs}\right.$ from $\mathrm{Pb}^{2+}$ ) it has been possible to determine that electrons are preferentially located on the 111 planes of $\mathrm{TiO}_{2}$ truncated octahedra, while holes in contrast concentrate preferentially on the 100 facets of these particles. According to this, if one enzyme is attached predominantly on one of these two faces, then, it will be in better contact either with electrons and holes, depending on where the enzyme is located. If the enzyme supported on this type of morphologically defined $\mathrm{TiO}_{2} \mathrm{NPs}$ offers an open channel for electron migration to reach the active center from the semiconductor, then, no mediator or cofactor would be needed. Of course, this preassembled semiconductor-enzyme conjugate should probably require of semiconductor samples with defined particle morphology and adequate particle size and also of adequate enzymes having pathways to channel electrons or holes from the enzyme external surface to the internal active site. These enzymes would be 
suitable for operation in the absence of mediators and cofactors. Thus, although this approach is probably not general and limited to a few examples, those examples would be of large interest as a proof of principle of the direct channeling of electrons from the semiconductor to the enzyme. As it will be commented below, hydrogenase and $\mathrm{CO}_{2}$ reductase are two classes of enzymes that have been reported that they can operate in combination with $\mathrm{TiO}_{2}$ as photocatalyst in the absence of mediators and cofactors.

To experimentally gain insight into the possibility of electron injection directly from the semiconductor to the enzyme, transient absorption spectroscopy appears as a very useful tool. For instance, transient absorption spectra of P25 suspensions in water show a signal with lifetime of about $1 \mu \mathrm{s}$. This transient in water is very short compared to the lifetime of the charge separation state of this semiconductor in acetonitrile or other solvents, in which it can

reach tens of microseconds. ${ }^{[80,81]}$ Most probably water, either as electron donor or acceptor, is quenching electron-hole pairs in photoexcited $\mathrm{TiO}_{2}$, shortening the lifetime of charge separation in this medium. ${ }^{[81]}$ The transient spectrum of $\mathrm{TiO}_{2}$ in water is a continuous absorption in the whole wavelength range from the UV to visible region, with no independent band for electrons and holes. If one enzyme is attached to P25, then, direct electron injection from $\mathrm{TiO}_{2}$ to the enzyme should lead to a shortening of the lifetime of electrons in P25 as consequence of their quenching or, alternatively, to an increase in the lifetime of holes as consequence of the selective removal of electrons and the impossibility of holes to recombine with electrons that have migrated to the enzyme. Both situations, shortening of electron lifetime or increase of hole lifetime have been observed in previous cases for quenchers, when monitoring the charge separation state of the $\mathrm{TiO}_{2} \cdot{ }^{\left[{ }^{[0]}\right.}$ What is important in the transient absorption measurement is to observe a clear variation of the temporal profile of the P25 transient signal, as consequence of the presence of increasing concentrations of the enzyme. Routine application of transient absorption spectroscopy techniques can serve to determine in which cases mediators and cofactors are not needed and in which other cases photobiocatalytic systems would not work without electron relays. Unfortunately, transient absorption spectroscopy still has to be used as a routine technique for photochemical characterization in photocatalytic systems.

\section{Photobiocatalysis for aerobic oxidations}

Cytochrome P450 is a monooxygenase enzyme that is able to introduce an oxygen atom at the $\alpha$ - or $\beta$ - position of long chain fatty acids using $\mathrm{H}_{2} \mathrm{O}_{2}$ as oxidizing reagent. ${ }^{[82]} \mathrm{H}_{2} \mathrm{O}_{2}$ is formed in the cells as consequence of the cellular respiration metabolism and is a natural oxygen reactive species present in the cytosol. As commented earlier, when a semiconductor is 
illuminated with photons of sufficient energy and electrons and holes are generated, electrons can be efficiently captured by oxygen if this gas is present. Therefore, virtually all photocatalytic systems operating under ambient conditions, in the presence of oxygen, generate ROS as consequence of this efficient trapping of conduction band electrons by oxygen. The primary species after accepting one electron is superoxide $\mathrm{O}_{2}^{-}$, but this primary species is strongly basic and is protonated by water to form $\mathrm{OOH}$ hydroperoxyl radicals that can end up in $\mathrm{H}_{2} \mathrm{O}_{2}$ by a sequence of a second electron and protonation step (Eq. 1). Therefore, the combination of monooxygenase $\mathrm{P} 450$, requiring $\mathrm{H}_{2} \mathrm{O}_{2}$ as oxidant, and a semiconductor irradiated in the presence of oxygen to provide stationary amounts of $\mathrm{H}_{2} \mathrm{O}_{2}$ from oxygen could, in principle, promote the hydroxylation of fatty acids (Scheme 18).

This concept has been experimentally proved, achieving in equal amounts both the $\alpha$-and $\beta$ - isomers of hydroxymyristic acid using P450/CdS as photobiocatalytic system that operates analogously to the reaction where $\mathrm{P} 450$ oxidation of myristic acid is initiated by $\mathrm{H}_{2} \mathrm{O}_{2} \cdot{ }^{[82]}$ Photobiocatalytic oxidation may have several advantages with respect to the chemical oxidation, the most important one being the facile on/off control of the reaction by turning the light on and off. It should be, however, commented that the stationary concentration of $\mathrm{H}_{2} \mathrm{O}_{2}$ generated photocatalytically is generally low, typically around $m M$, due to the fact that $\mathrm{H}_{2} \mathrm{O}_{2}$ also decomposes photocatalytically very easily and it is not stable under irradiation conditions. Therefore, a stationary concentration is reached due to the continued formation from $\mathrm{O}_{2}$ and decomposition of $\mathrm{H}_{2} \mathrm{O}_{2}$ as indicated in Scheme 19.

The key point is that the stationary concentration of $\mathrm{H}_{2} \mathrm{O}_{2}$ reached in the photocatalytic reduction of $\mathrm{O}_{2}$ has to be sufficiently high and compatible with the operation of the enzyme. It should be, however, commented that most of the peroxidase and catalase enzymes can operate with low $\mathrm{H}_{2} \mathrm{O}_{2}$ concentration. 


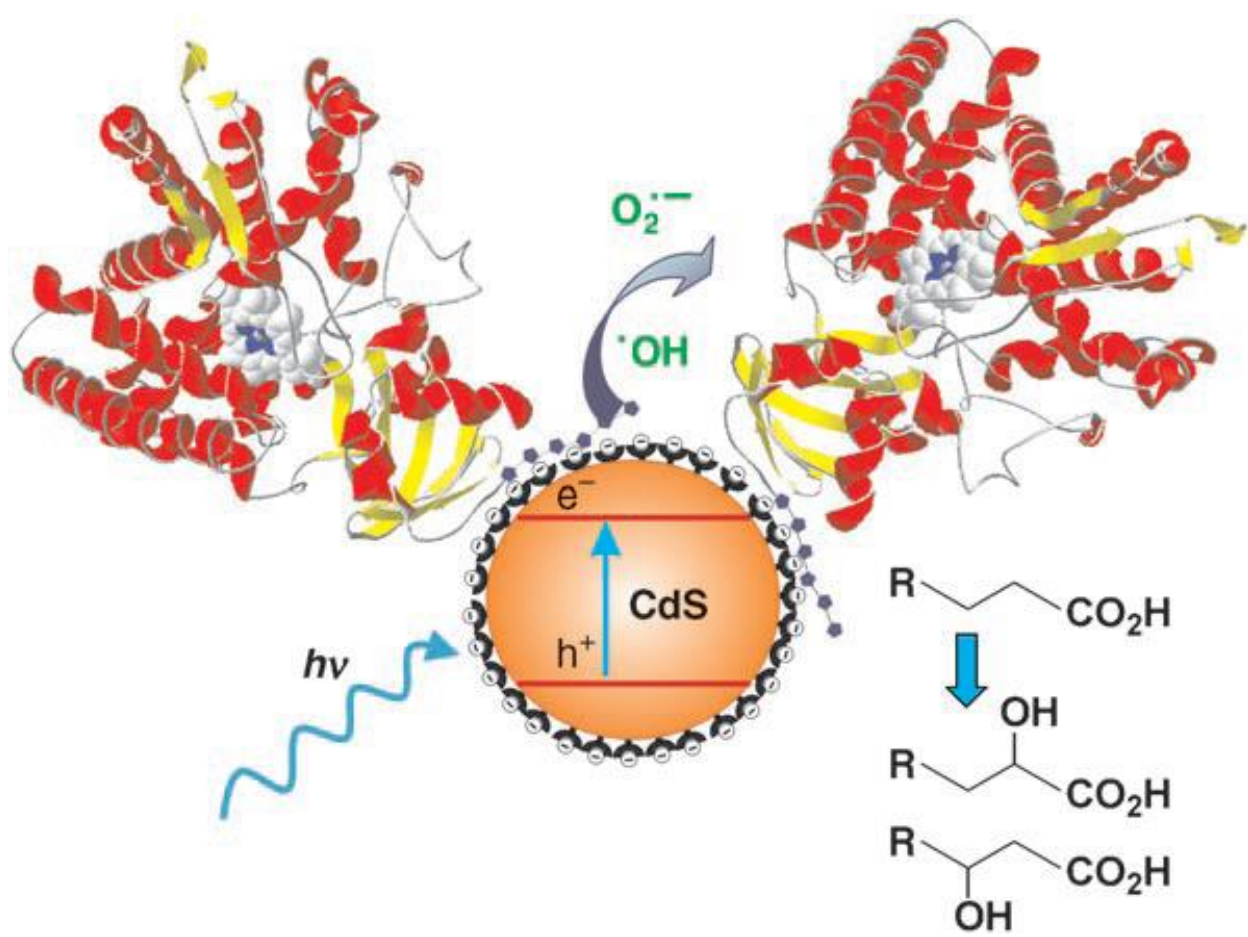

Scheme 18. Monooxygenation of myristic acid $\left(\mathrm{R}=\left(\mathrm{CH}_{2}\right)_{10} \mathrm{CH}_{3}\right)$ using $\mathrm{P} 45 \mathrm{O}_{\mathrm{BSb}} / \mathrm{CdS}$ quantum dots nanohybrids (Taken with permission from ref ${ }^{[82]}$ ).

$$
\begin{aligned}
& \text { Photocatalytic } \mathrm{H}_{2} \mathrm{O}_{2} \text { generation: } \mathrm{O}_{2}+2 \mathrm{H}^{+}+2 \mathrm{e}^{-} \rightarrow \mathrm{H}_{2} \mathrm{O}_{2} \\
& \text { Photocatalytic } \mathrm{H}_{2} \mathrm{O}_{2} \text { decomposition: } \mathrm{H}_{2} \mathrm{O}_{2}+2 \mathrm{~h}^{+} \rightarrow \mathrm{O}_{2}+2 \mathrm{H}^{+}
\end{aligned}
$$

Identical reaction rates for both processes leads to a stationary $\mathrm{H}_{2} \mathrm{O}_{2}$ concentration.

Scheme 19. Photocatalytic steady state generation of $\mathrm{H}_{2} \mathrm{O}_{2}$ by oxygen reduction.

\section{Photobiocatalysts for hydrogen evolution}

Platinum as cocatalyst has as main role to act as $\mathrm{H}_{2}$ evolving center, forming $\mathrm{H}_{2}$ with the minimal overpotential ${ }^{[83]}$. However, Pt as a noble metal is extremely costly and its limited availability will thwart most of the commercial applications of photobiocatalytic systems if they contain Pt as component. For this reason, even though Pt is highly efficient as hydrogen evolving center, there is a need to replace this precious metal by other affordable alternatives.

In this context, electrochemical studies have also shown the high activity of hydrogenases to produce $\mathrm{H}_{2}$ also with low overpotential, comparable to that needed with $\mathrm{Pt}$ that is only of a few $\mathrm{mV}$ over the thermodynamic value. ${ }^{[84]}$ In addition, hydrogenases may have the advantage over Pt NPs that they are not poisoned by the presence of $\mathrm{CO}, \mathrm{H}_{2} \mathrm{~S}$ or even $\mathrm{O}_{2}$ that are known to strongly deactivate Pt, either by strong adsorption or by preferential electron quenching.

Considering the well documented efficiency of hydrogenases in electrochemical $\mathrm{H}_{2}$ generation, it is not surprising that these enzymes can also act as replacement of Pt NPs in 
photobiocatalytic systems aimed at the conversion of light into hydrogen. In these cases, hydrogen could be considered as the product of the enzymatic process triggered by light absorbed by the semiconductor, occurring a vectorial electron transfer from the photocatalyst conduction band to the dehydrogenase. Thus, for instance, an assembly consisting in $\mathrm{TiO}_{2} \mathrm{P} 25$ as semiconductor, a ruthenium polypyridyl dye having peripheral phosphonic groups to bind to the $\mathrm{TiO}_{2}$ surface as light harvester and [NiFeS] hydrogenase as $\mathrm{H}_{2}$ evolution center exhibits at $\mathrm{pH} 7$ and $25^{\circ} \mathrm{C}$ using triethanolamine as sacrificial electron donor a TOF of $50\left(\mathrm{molH}_{2}\right) \mathrm{s}^{-1}(\mathrm{~mol}$ total hydrogenase) ${ }^{-1}$ (Scheme 20). ${ }^{[85]}$

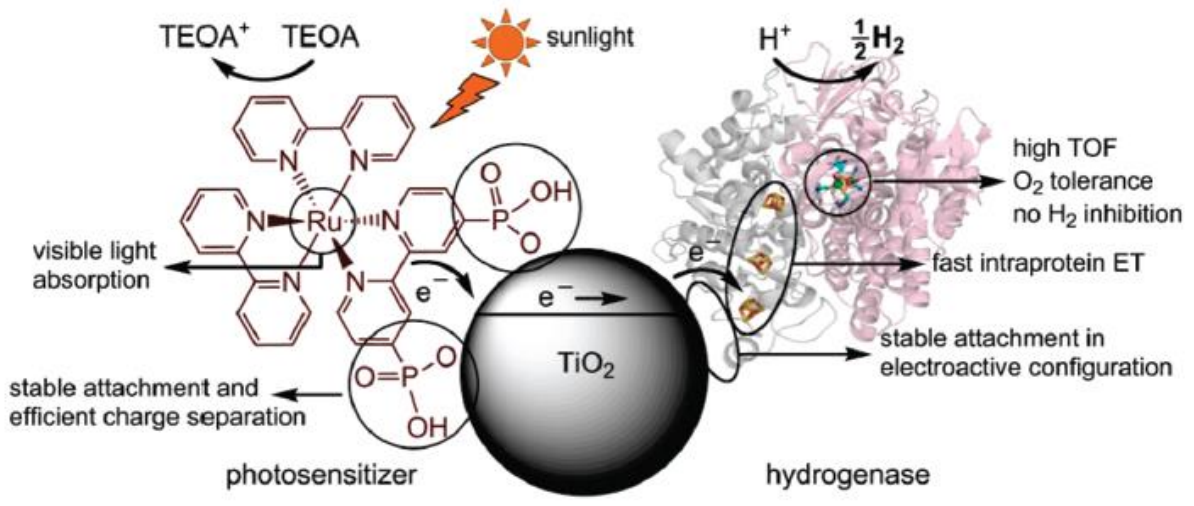

Scheme 20. Operation and advantages of a photobiocatalytic system based on $\mathrm{TiO}_{2}$ semiconductor, ruthenium polypyridyl dye as light harvester and a $\{\mathrm{NiFeS}\}$ hydrogenase as cocatalyst in the absence of cofactors and electron mediators (TEOA: triethanolamine). (Figure taken with permission from ref ${ }^{[85]}$ ).

An important parameter to be considered in the operation of this photobiocatalytic system for the generation of $\mathrm{H}_{2}$ is $\mathrm{pH}$ of the aqueous solution. It was found that the hydrogenase photobiocatalytic system operates adequately in the $\mathrm{pH}$ range around neutrality $(\mathrm{pH} 5-8)$. Higher $\mathrm{pH}$ values lead to the desorption of the ruthenium complex from $\mathrm{TiO}_{2}$. Lower $\mathrm{pH}$ values could result in inactivation of the enzyme. With regard to the temperature, it was determined that the TOF for $\mathrm{H}_{2}$ production increases from $10 \mathrm{~s}^{-1}$ to $72 \mathrm{~s}^{-1}$ when the temperature increases from 5 to $45{ }^{\circ} \mathrm{C}$. Operation of the system at $45{ }^{\circ} \mathrm{C}$ was considered as an evidence of the thermal stability of the enzyme in the photobiocatalytic system.

This remarkable high photocatalytic efficiency seems to derive from the combination of several favorable factors including excellent attachment on $\mathrm{TiO}_{2}$ of both, the photosensitizer and the hydrogenase, efficient light harvesting and electron injection activity of ruthenium polypyridyl dye, fast intraprotein electron channeling from $\mathrm{TiO}_{2}$ conduction band to the prostetic center of hydrogenase without the need of mediator among other requirements. The excellent anchoring of [NiFeS]-hydrogenase to $\mathrm{TiO}_{2}$ seems to derive from the presence in the 
enzyme of lateral carboxylate groups. Carboxylic acid groups are known to attach strongly to the $\mathrm{TiO}_{2}$ surface ${ }^{[85]}$.

As indicated in a previous section, one of the features of this photobiocatalytic system that deserves further study is the reasons why it does not require cofactors and mediators and that the migration of $\mathrm{TiO}_{2}$ conduction band electrons to the enzyme active site takes place with interfacial channeling. The mechanism through which electrons are directly injected to the hydrogenase and the nature of the channel of electrons needs to be fully substantiated in order to take the maximum advantage of this system.

Since both ruthenium polypyridyl complex and hydrogenase enzyme have to be attached to the surface of $\mathrm{TiO}_{2} \mathrm{NPs}$, their relative concentration, and even, the order in which these two components are supported on the photocatalyst is important in order to prepare a sample of the system with the optimal photocatalytic activity. For instance, if a high concentration of ruthenium polypyridyl complex having phosphate units is employed, then almost complete coverage of the $\mathrm{TiO}_{2}$ surface could be achieved and, then, hydrogenase will not be able to find suitable positions on $\mathrm{TiO}_{2}$ to anchor. Accordingly, high loadings of ruthenium polypyridyl can be detrimental from the point of view of the photocatalytic activity. In fact, it may happen that just a small concentration of ruthenium polypyridyl complex could be sufficient to harvest most of the photons reaching $\mathrm{TiO}_{2} \mathrm{NPs}$ due to their high molar absorptivity. In this case, higher loading of the ruthenium complex will not increase the photoactivity of the system and will, probably, play a negative effect due to the limitation on the loading of hydrogenase on $\mathrm{TiO}_{2}$. Since surface attachment of both light harvester and hydrogenase are considered to be a prerequisite, the presence of phosphate and other ions in the solution was also found to be strongly detrimental for the operation of the photobiocatalytic system by competing with the anchoring of the ruthenium complex and hydrogenase enzyme for attachment to the $\mathrm{TiO}_{2}$ surface.

Another observation regarding the ruthenium complex-P25-hydrogenase system is that the photocatalytic activity data was frequently hard to reproduce, observing variations of about $50 \%$ in the amount of hydrogen generated upon exposure of the system to daylight at the open air for just $0.5 \mathrm{~h}$. It was determined that low-intensity daylight and atmospheric $\mathrm{O}_{2}$ are apparently sufficient to promote the oxidative degradation of a large percentage of the enzyme decreasing significantly the photocatalytic activity of the system. Therefore, it is strongly recommended that all the preparation steps should be carried out protecting the system from ambient light or from atmospheric $\mathrm{O}_{2}$. Probably this good practice should also be extended to the preparation of any photobiocatalytic system or, at least, the issue of enzyme stability under normal operational laboratory conditions should be fully substantiated. This 
degradation of the hydrogenase enzymatic activity would be a consequence of the generation of sufficiently high reactive ROS under these conditions. It should be noted that total absence of $\mathrm{O}_{2}$ is a prerequisite in the photocatalytic water splitting, so no ROS are generated when $\mathrm{H}_{2}$ evolves. Overall, the $\mathrm{H}_{2}$ TOF achieved with this system, either calculated with respect to the

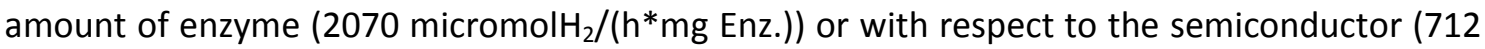
micromolH $\left.\mathrm{H}_{2} /\left(\mathrm{h} * \mathrm{~g} \mathrm{TiO}_{2}\right)\right)$ is among the highest ever reported for any light-driven $\mathrm{H}_{2}$ production system, including not only enzymatic, but also noble metal-based photocatalyst. This fact is particularly notable considering that no cofactor or mediator is required in this photobiocatalytic system. The issue of photostability of the system for long irradiation periods appears, however, as a possible limitation for the scale up of the system and is a point that deserves a detailed study.

In a further elaboration of photobiocatalyst for $\mathrm{H}_{2}$ generation, a photoelectrochemical cell with two compartments separated by a porous Nafion membrane having an anodized titanium electrode on metal titanium as photoanode connected electrically to the photocathode containing hydrogenase enzyme has been reported (See Scheme 21). ${ }^{[86]}$ The system operates in the absence of sacrificial electron donor and producing overall water splitting (simultaneous generation of $\mathrm{H}_{2}$ and $\mathrm{O}_{2}$ in stoichiometric amounts). In this photoelectrochemical cell, the enzyme and semiconductor are physically separated and connected electrically. This situation can have advantages with respect to most common experimental setup in terms of no need of surface anchoring and higher stability. However, efficiency of the cell can be limited by the slow activation of the enzyme. 


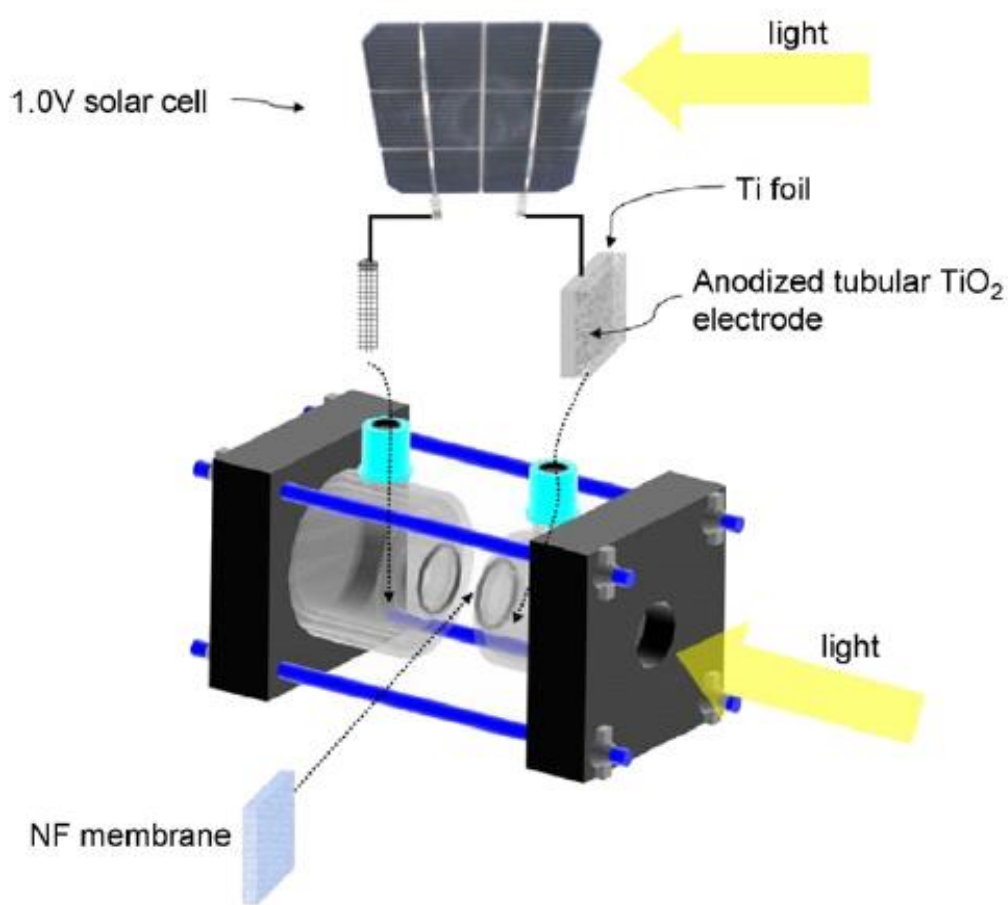

Scheme 21. Components and operation mechanism of overall water splitting with separate compartments for oxygen and hydrogen generation in the absence of sacrificial electron donors assisted by a bias potential from a solar cell. NF: Nafion. (Figure taken with permission from ref ${ }^{[86]}$ ).

The system operates with an external bias provided by a solar cell that assists the overall water splitting without the need of sacrificial agents. The anodized tubular titanium electrode has to be previously thermally annealed at temperatures between 450 and $650{ }^{\circ} \mathrm{C}$ to increase the crystallinity of the anatase phase, produce the sintering of the NPs constituting the tubes and to achieve the highest photocatalytic activity. Similarly, among possible hydrogenases, it was found that the one obtained from Pyrococus Furiosus was the best performing one. The data obtained showed that the origin of the enzyme plays an important role on the photocatalytic activity. This enzyme was present in solution in the cathode in which the working electrode was also anodized titania. Under these conditions, oxygen and hydrogen evolved in quasi stoichiometric amounts separately in the photoanode and cathode compartments, respectively. The maximum $\mathrm{H}_{2}$ production rate was $40 \mu \mathrm{mol} /\left(\mathrm{cm}^{2} \cdot \mathrm{h}\right)$ that roughly corresponds to $9 \mathrm{I} /\left(\mathrm{m}^{2} \cdot \mathrm{h}\right)$. Interestingly, extrapolation of these numbers to a $6.5 \mathrm{~h}$ sunlight day in a field having a surface of $100 \times 100 \mathrm{~m}$ would lead to the production of $585 \mathrm{~m}^{3} \mathrm{H}_{2}$ under ambient conditions. It remains, however to be determined the mechanism through which electrons reaching cathode are transferred to the hydrogenase in the solution, particularly the transport mechanism of the electron to the active site of the enzyme. It could 
be possible that the presence of an electron mediator could enhance the $\mathrm{H}_{2}$ production rate even further.

\section{Photobiocatalysis for $\mathrm{CO}_{2}$ reduction}

An extension of the previous photocatalytic system, but replacing hydrogenase by a $\mathrm{CO}_{2}$ reducing enzyme $\left(\mathrm{CO}_{2}\right.$ dehydrogenase $\left.\mathrm{I}, \mathrm{CODH} \mathrm{I}\right)$ obtained from the anaerobic microbe $\mathrm{Ch}$ (Carboxydothermus hydrogenoformans) has been applied to the reduction of $\mathrm{CO}_{2}$ to $\mathrm{CO}^{[87]} \mathrm{As}$ in the previous case using hydrogenase, the photocatalytic system operates by photoinduced electron injection from a ruthenium polypyridyl complex to the active center of CODH I through the intermediacy of $\mathrm{TiO}_{2} \mathrm{NPs}$ using mercaptoethylsulphonate (MES) as sacrificial electron donor with no need of cofactor or mediator. It was found that the photocatalytic activity of the system increases with the loading of enzyme, indicating that the rate determing steps in this photobiocatalytic $\mathrm{CO}_{2}$ reduction to $\mathrm{CO}$ are the processes taking place at the enzyme. It was, however, observed that the photobiocatalytic system decreases in activity in a few hours. This lack of stability under operation conditions contrasts with that of the analogous photobiocatalyst for $\mathrm{H}_{2}$ evolution based on dehydrogenase. ${ }^{[87]}$ This fact was presumed to be related to the higher endoergonicity of $\mathrm{CO}_{2}$ reduction compared to $\mathrm{H}_{2}$ generation, although other possibilities, particularly detachment of the enzyme from the $\mathrm{TiO}_{2}$ surface, could also explain the observed deactivation.

Evaluation of the nature of the semiconductor for this CODH I-containing photocatalyst among $\mathrm{P} 25$, anatase, rutile, $\mathrm{ZnO}$ and $\mathrm{SrTiO}_{3}$ shows that the best performing semiconductor is P25 and that the amount of $\mathrm{CO}$ evolved depends significantly on the nature of the semiconductor as well as the nature and concentration of the ruthenium dye and sacrificial electron donors. The combination that was found to give the highest $\mathrm{CO}$ evolution rate comprises mercapto ethyl sulfonate, ruthenium polypyridyl and CO-dehydrogenase II. In the last case, optimization of the orientation of this CO-dehydrogenase II enzyme with respect to $\mathrm{TiO}_{2}$ surface can be achieved without requiring linkers to attach $\mathrm{CODH}$ II to the $\mathrm{TiO}_{2}$ surface. ${ }^{[87]}$

\section{Enzyme mimicking}

One further development of photobiocatalytic systems would be the design and preparation of synthetic molecules or semiconductor-cocatalyst conjugates that contain the photosensitizers attached to a model of the active center of the enzyme. ${ }^{[88]}$ The power of this strategy would be that by learning the operation mechanism of enzymes, an artificial system targeting a photocatalytic process considerably more simple and affordable obtained by biomimetic design could be available in large scale. This approach could be specially appealing for solar fuel production that requires very stable photobiocatalysts to ensure long-term 
stability of the material. In this context, one of the enzymes whose active center can be mimicked are hydrogenases that will be applicable for $\mathrm{H}_{2}$ production.

Towards this goal of mimicking hydrogenases coupled to light harvester, a silafluorene having $[\mathrm{FeFe}] \mathrm{CO}_{6}$ unit has been synthesized (Scheme 22 ). The system has been characterised and tested for $\mathrm{H}_{2}$ generation in acetonitrile containing triethylamine as electron-donor and trifluoroacetic acid as $\mathrm{H}^{+}$source.

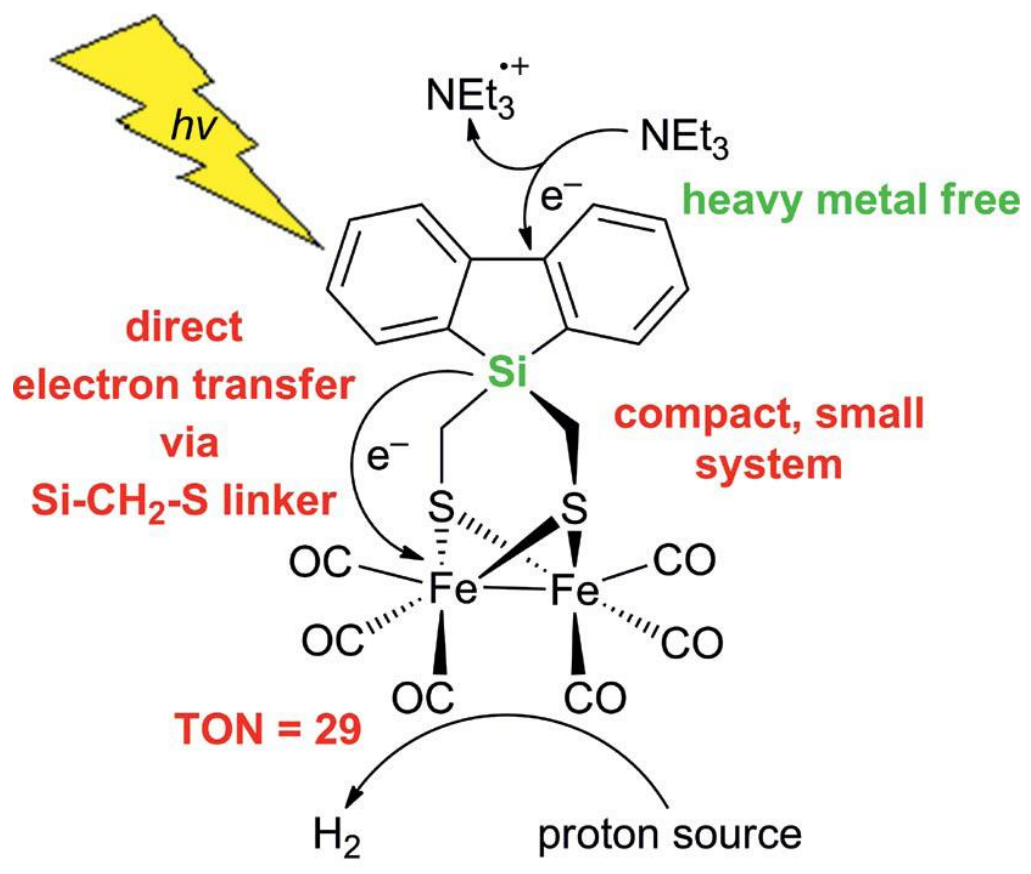

[FeFe]- hydrogenase mimic

Scheme 22. Structure and operation mechanism of the light-driven production of hydrogen by [FeFe]-hydrogenase mimic. (Taken with permission from ref ${ }^{[88]}$ ).

Although the system based on the silafluorene represents a proof of concept of mimicking the [FeFe] hydrogenase active center, there is still a considerable room for improvement of the photocatalytic activity. In addition, since the biphenyl chromophore only absorbs in the UV region, the mimic system does not have response under visible light irradiation and this limitation should be overcome for its use as solar photocatalyst. The rationale behind the use of $\mathrm{Si}$, a non-biological element, in the chromophore center transferring electrons to the $b$ center was to avoid more expensive noble metals typically used as mediators, while still allowing electron migration. However, it seems that other more appropriate heteroatoms with higher electron donor ability should be desirable. Also, it would be highly desirable that the photosensitizer - [FeFe] center conjugate would be soluble in water, rather than in organic 
solvents. This water solubility could be achieved by introducing appropriate substituents to increase the hydrophilicity of the conjugate. Another point is that the source of hydrogen should be water and not a strong carboxylic acid. Furthermore, the two major limitations to be overcome are the low quantum efficiency of $\mathrm{H}_{2}$ generation and the poor stability of the system. Specifically, it was found that the $\mathrm{CO}$ ligands around the [FeFe] centers progressively disappear upon irradiation. Interestingly, when $\mathrm{H}_{2}$ evolves the photochemical stability of the $\mathrm{Fe}(\mathrm{CO})_{3}$ centers is higher than under conditions in which no $\mathrm{H}_{2}$ is generated, this meaning that the two processes, $\mathrm{H}_{2}$ generation and active center decomposition, are probably competing. In any case, the silafluorene compound exhibits a TON of 29 that is currently among the records for a simple molecule acting as hydrogenase mimic.

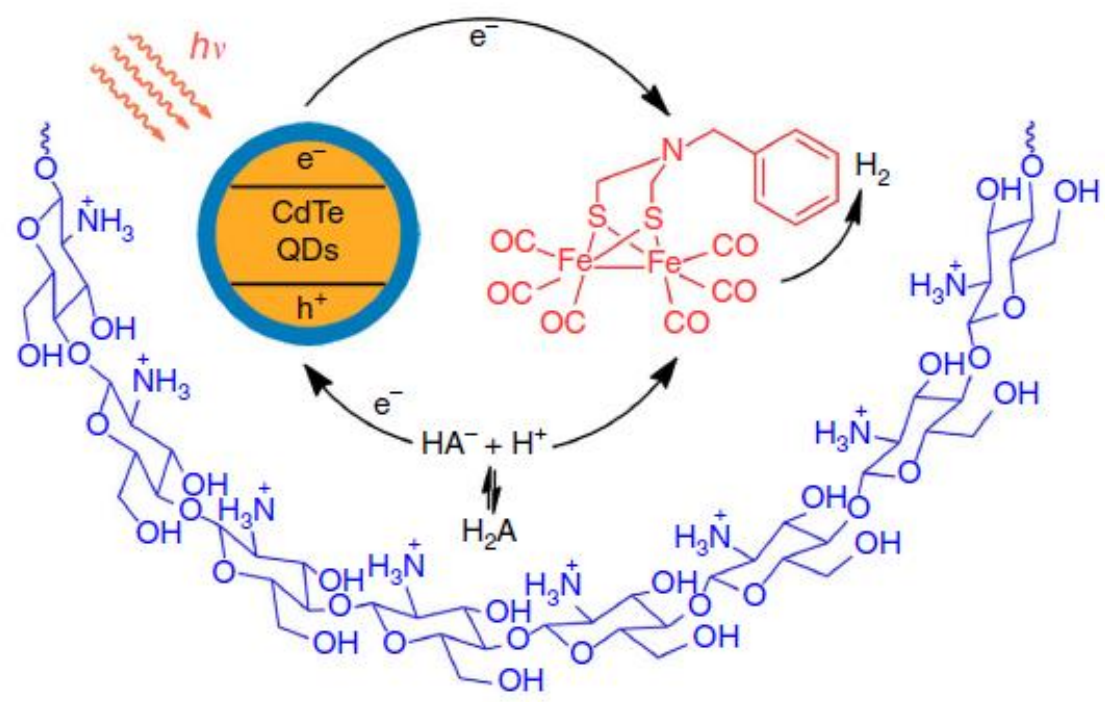

Scheme 23. Photocatalytic system for $\mathrm{H}_{2}$ generation based on chitosan-confined mimic of the diiron subsite of [FeFe]-hydrogenase using $\mathrm{CdTe}$ quantum dots as semiconductor and ascorbic acid $\left(\mathrm{H}_{2} \mathrm{~A}\right)$ as electron donor. (Taken with permission from ref. ${ }^{[89]}$ ).

While in the previous example, the idea was to build a small molecule having covalently attached the photosensitizer and the $\{\mathrm{Fe}, \mathrm{Fe}\}$ hydrogenase center, a more flexible approach is just to have both components i.e. light harvesting, and the hydrogenase diiron center in proximity but without covalent binding. This more versatile approach has been recently developed by using chitosan, a natural biopolymer of glucosamine, to embed, due to electrostatic interaction, CdTe quantum dots and a diiron hexacarbonyl dithio center bonded to benzylamine. ${ }^{[89]}$ The CdTe quantum dots were capped with mercaptopropionic acid (MP) to increase the affinity of these quantum dots for chitosan. The system operates using ascorbic acid in methanol-water mixture to provide protons and to act also as hole quencher (Scheme 
23). The optimal conditions were when MP-CdTe (0.86 micromol/I), $\{\mathrm{Fe}, \mathrm{Fe}\}$ hydrogenase (10 micromol/l) mimic were embedded in the fibrils of chitosan at a concentration of $1 \mathrm{~g} / \mathrm{l}$, whereby a $\mathrm{H}_{2}$ evolution of $1.27 \mathrm{ml}$ in $10 \mathrm{~h}$ was achieved. It was proposed that the enhanced efficiency and durability of the photocatalytic system derives from the strong interaction and close contact between $\mathrm{CdTe}$ quantum dots, the $\{\mathrm{Fe}, \mathrm{Fe}\}$ center and ascorbic acid in the chitosan environment provided by chitosan.

By fluorescence intensity measurements, it was found that chitosan stabilizes CdTe quantum dots preventing their aggregation. Electrochemical measurements of $\{\mathrm{Fe}, \mathrm{Fe}\}$ hydrogenase center mimic in the absence and in the presence of chitosan indicate that the biopolymer stabilizes mixed valences and low valence states of $\mathrm{CO}_{3} \mathrm{Fe}-\mathrm{FeCO}_{3}$ motif, making possible the build-up in solution of sufficiently high concentration of these electron reservoirs involved in $\mathrm{H}_{2}$ generation. In addition, laser flash photolysis studies have provided direct evidence for the occurrence of photoinduced electron transfer from excited $\mathrm{CdTe}$ quantum dots to $(\mathrm{CO})_{3} \mathrm{Fe}-\mathrm{Fe}(\mathrm{CO})_{3}$ centers, the transient absorption at ca. $400 \mathrm{~nm}$ being attributable to the mixed $(\mathrm{CO})_{3} \mathrm{Fe}^{1}-\mathrm{Fe}^{0}(\mathrm{CO})_{3}$ species. ${ }^{[89]}$ Overall this study shows the opportunity that assembling of photocatalytic components by intermolecular forces developing supramolecular systems can provide to mimic natural photosynthetic centers, replacing the protein scaffold by other type of more widely available polymer.

In another example of mimicking the prostetic centers of enzymes, a Fe" porphyrazin was synthesized and after anchoring on an ion-exchanging Amberlite CG-400 resin, the resulting active center-polymer material tested for the decolorization of rhodamine $B$ dye $(\mathrm{RhB})$ either in solution at acid or neutral pH or adsorbed on the resin (Scheme 24). ${ }^{[90]}$ The mechanism of the decolorization involves coordination of $\mathrm{Fe}^{\prime \prime}$ porphyrazin with $\mathrm{O}_{2}$ to form an adduct that upon excitation undergoes electron transfer generating $\mathrm{Fe}^{\prime \prime \prime}$ and $\mathrm{O}_{2}{ }^{-}$superoxide anion radical initially bonded to the iron cation. This process generates undetermined ROS that can migrate reaching and promoting the degradation of the RhB dye under visible light irradiation.

$$
\begin{aligned}
& \mathrm{Fe}^{\mathrm{II}} \mathrm{Pz}(\mathrm{hmdtn})_{4} \stackrel{\mathrm{O}_{2}}{\longrightarrow} \mathrm{Fe}^{\mathrm{II}} \mathrm{Pz}(\text { hmdtn })_{4} \stackrel{h v}{\longrightarrow} \stackrel{\mathrm{O}_{2}}{\longrightarrow} \stackrel{\mathrm{Oe}^{\mathrm{II}} \mathrm{Pz}(\mathrm{hmdtn})_{4}}{\longrightarrow} \longrightarrow \\
& \longrightarrow \mathrm{O}_{2}^{-}-\mathrm{Fe}^{\mathrm{III}} \mathrm{Pz}(\text { hmdtn })_{4} \stackrel{\text { or }}{\longrightarrow}\left[\mathrm{O}=\mathrm{Fe}^{\mathrm{IV}} \mathrm{Pz}(\text { hmdtn })_{4}\right]^{+}
\end{aligned}
$$

Scheme 24. Elementary steps in the reaction of $\mathrm{O}_{2}$ with the iron(II) tetrahydoxymethyltetra(1,4-dithiin) porphyrazine (abbreviated as $\left.\mathrm{FePz}(\mathrm{hmdtn})_{4}\right)$. (Reproduced with permission from ref. ${ }^{[90]}$ ). 
In another work also aimed at developing photobiocatalytic systems mimicking enzyme centers, an iron thiolate complex insoluble in water has been suspended in aqueous solution using sodium dodecylsulfate (SDS) surfactant. The presence of SDS leads to the formation of micelles containing iron thiolate that was considered as a simplified model of $\{\mathrm{Fe}, \mathrm{Fe}\}$ hydrogenase center. ${ }^{[91]}$ Irradiation of the $\{\mathrm{Fe}, \mathrm{Fe}\}$ hydrogenase model dispersed in SDS micelle using eosin $Y$ as sensitizer and triethylamine as sacrificial electron donor leads to the generation of $\mathrm{H}_{2}$ with a TON of $117 \mathrm{molH}_{2} / \mathrm{g}$ catalyst. Scheme 25 summarizes the mechanism for $\mathrm{H}_{2}$ generation that involves changes in the oxidation state of the $\{\mathrm{Fe}, \mathrm{Fe}\}$ model. It was found that the stability of this system is limited by the gradual degradation of the eosin dye under irradiation conditions.

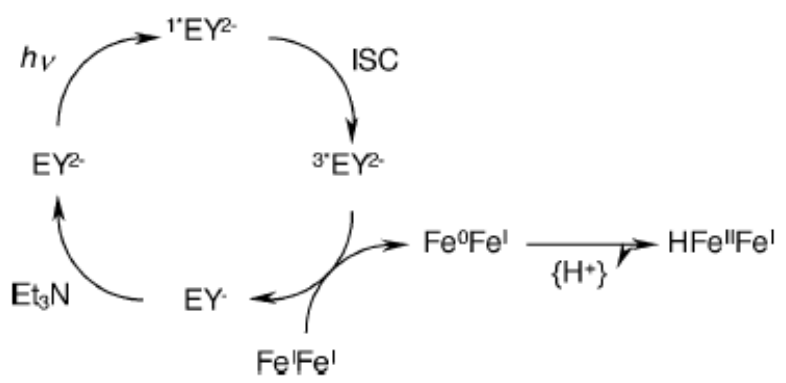

Scheme 25. Mimic of the center mimicking hydrogenase $\{\mathrm{Fe}, \mathrm{Fe}\}$ active center and proposed mechanism for the formation of the corresponding hydride intermediate in the system based on eosin $\mathrm{Y}(\mathrm{EY})$ dye as light harvester and triethylamine $\left(\mathrm{Et}_{3} \mathrm{~N}\right)$ as electron donor in aqueous SDS solutions at pH 10.5. (ISC: intersystem crossing from singlet to the triplet excited state) (Taken with permission from ref. ${ }^{[91]}$ ).

\section{Mediators in photobiocatalytic systems}

As commented earlier, one of the main problems in the design of a photobiocatalyst is the need of a mediator that should be able to reduce the cofactor that subsequently will activate the prostetic center of the enzyme. One fact that is well established is the strong dependence of the nature of the mediator on the efficiency of the photobiocatalytic system.

Concerning the nature of the mediator, one study that has illustrated the importance of the structure of these components on the catalytic activity has used laccase as a case of study. ${ }^{\left[{ }^{22]}\right.}$ Laccase is able to oxidize NADPH to $\mathrm{NADP}^{+}$that subsequently can be a cofactor of alcohol dehydrogenase to oxidize alcohols. A suitable mediator should shuttle electrons from the laccase center to oxidize NADPH. Scheme 26 illustrates the laccase-mediator system coupled with alcohol dehydrogenase to catalyze the aerobic oxidation of alcohol. 

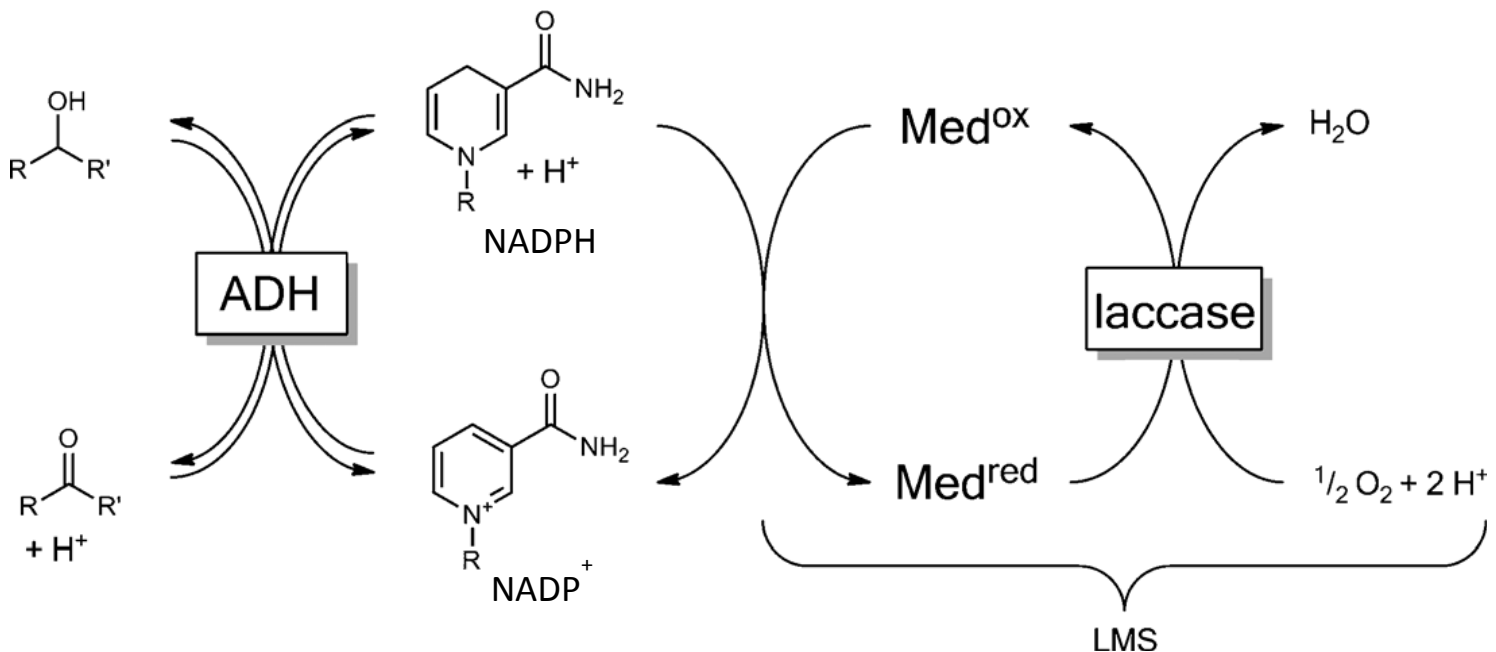

Scheme 26. Mechanism of alcohol oxidation by oxygen as oxidant using laccase and mediator. Med ${ }^{\mathrm{ox}}=$ oxidised mediator, Med ${ }^{\text {red }}=$ reduced mediator. (Figure taken with permission from ref ${ }^{[92]}$ ).

In that study, eighteen mediators were screened for the efficient reduction of laccase. Among them, acetosyringone and syringaldehyde, as well as caffeic acid were found the most efficient compounds to effect the generation of $\mathrm{NAD}^{+}$. Other molecules, even if they appear to be structurally closely related, are much less efficient or total inefficient for this purpose. This raises the issue of the current lack of a conceptual framework to rationalize or even predict the most suitable molecule mediator acting for each enzyme. Furthermore, it is likely that the most adequate mediator could also vary depending on the operation conditions and the origin of the enzyme.

A well-established methodology to promote visible light activity in $\mathrm{TiO}_{2}$ is doping, either with metal or non-metallic elements. ${ }^{[93-95]}$ In a study about the effect of P-doping on $\mathrm{TiO}_{2}$ for $\mathrm{NAD}^{+}$reduction, it was found that $\mathrm{NADH}$ regeneration using water as sacrificial electron donor can be achieved under visible light illumination by $\mathrm{P}$-doped $\mathrm{TiO}_{2} \cdot{ }^{[96]}$ The system requires a rhodium cyclopentadiene organometallic complex as mediator to shuttle electrons from $\mathrm{P}^{-\mathrm{TiO}_{2}}$ conduction band to $\mathrm{NAD}^{+}{ }^{[96]}$ It was found that the photocatalytic efficiency of NADH regeneration increases with the content of $\mathrm{P}$ in the doped $\mathrm{TiO}_{2}$ in the range from 0 to 6 at. \%, reaching a maximum NADH generation yield of $34.6 \%$. The beneficial influence of P doping on the visible light photocatalytic activity was attributed to the increase in the surface area of $\mathrm{TiO}_{2}$ upon doping and to the narrower band gap of the doped material allowing visible light excitation. Scheme 27 summarizes the operation mechanism. It should have been, however, convenient to show if other dopants act similarly and with the same efficiency in the photoregeneration of NADH. A logical follow up of this study would be to combine the 
photogeneration of NADH with some enzymatic system that uses this cofactor in a catalytic reduction, making an efficient visible-light photobiocatalytic system based on titania.

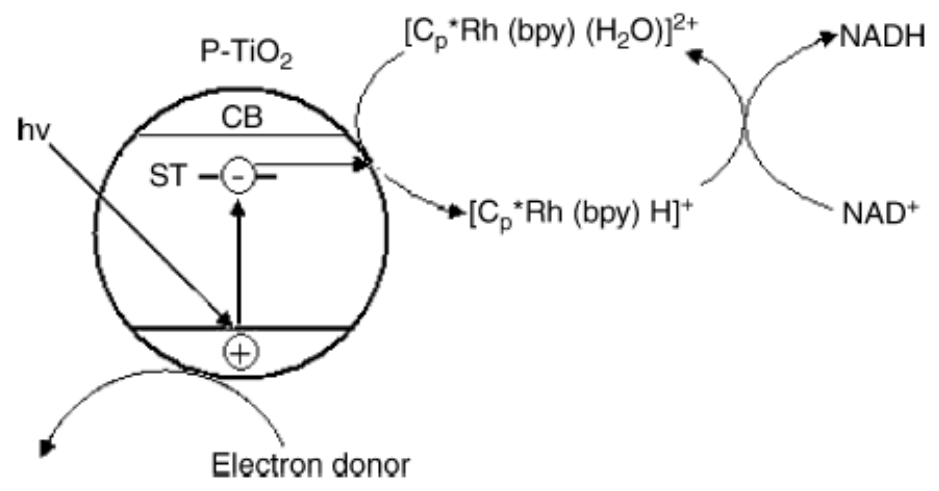

Scheme 27. Mechanism of photocatalytic NAD+ reduction based on $\mathrm{P}$-doped $\mathrm{TiO}_{2}$ and a rhodium complex as mediator. (Figure taken with permission from ref ${ }^{[96]}$ ).

In the search for simple organic molecules as mediators, there are several studies reporting the use of bipyridinium ions that have a chemical structure similar to $\mathrm{NAD}^{+}$and are also susceptible to accept hydride ions. One of these studies is focused on the operation of glutathione reductase (GR). Glutathione is a natural oligopeptide that acts as antioxidant in biological systems to control the oxidative stress in the cells caused by ROS generated in the cellular oxidation. Glutathione is a constituted by three aminoacids, the central one being cysteine that is able to form a disulfide bridge with another glutathione (Scheme 28). The redox pair constituted by glutathione (GSH) and the corresponding disulfide dimer (GSSG) is controlled by an enzyme that is able to perform GSSG reduction, namely GR. It has been found that GR can be activated photochemically using $\mathrm{Ru}(\mathrm{bpy})_{3}{ }^{2+}$ as photosensitizer absorbing visible light, $N, N^{\prime}$-bis(carboxyethyl)-4,4'-bipyridinium covalently attached to the enzyme as electron relay and EDTA as sacrificial electron donor. ${ }^{[97]}$ Based on the known behavior of the $\mathrm{Ru}(\mathrm{bpy})_{3}{ }^{2+}$ and viologens, it was proposed that the triplet excited state of $\mathrm{Ru}(\mathrm{bpy})_{3}{ }^{2+}$ generated upon visible light absorption is quenched by the bipyridinium ion, resulting in an electron transfer from the $\mathrm{Ru}$ complex as electron donor to bipyridinium as electron acceptor. Since bipyridinium is attached and immobilized to the modified GR enzyme these units can act as electron mediators, transporting this electron to the enzyme active site without the need of the natural cofactor. This electron relayed by bipyridiniums once in the center of GR promotes reduction of GSSG to GSH. The photocatalytic cycle is completed by EDTA giving one electron to the oxidized form of the photosensitizer. Scheme 28 illustrates the components of this photocatalytic system and the operation mechanism, the key point being that bipyridinium can 
efficiently perform two roles i.e. accepting one electron from $\mathrm{Ru}(\mathrm{bpy})_{3}{ }^{2+}$ triplet and as mediator providing the electron to the enzyme.

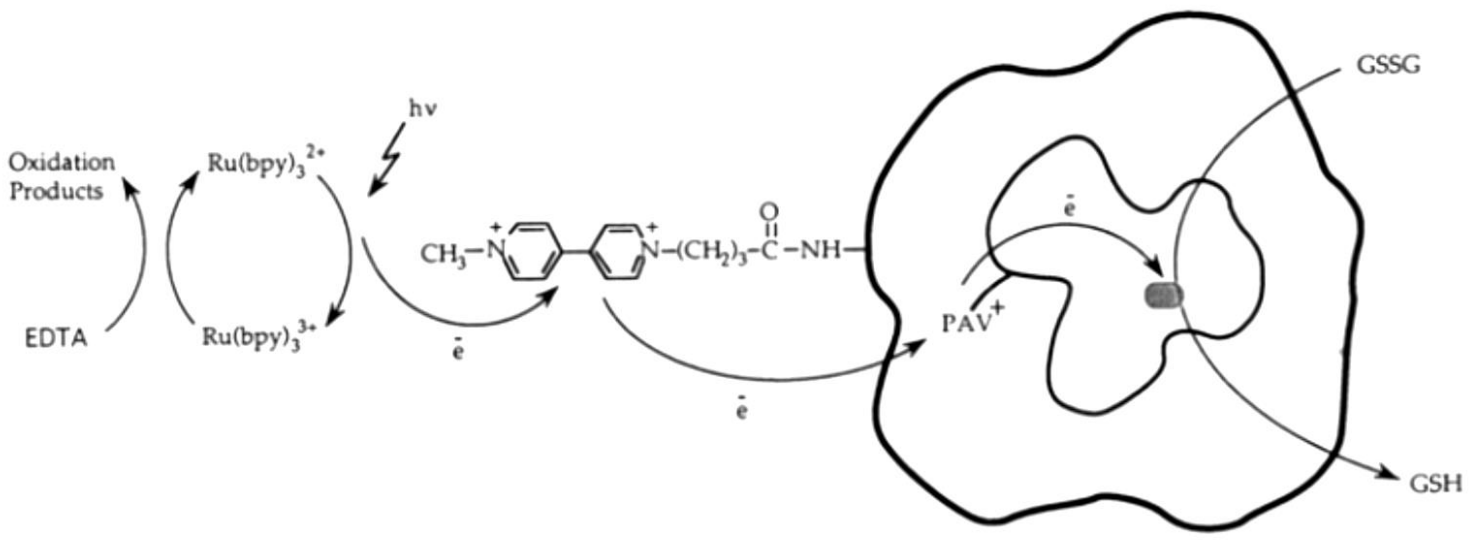

Scheme 28. Operation mechanism of GR promoted by visible-light photosensitized electron transfer between $\mathrm{Ru}(\mathrm{bpy})_{3}{ }^{2+}$ and a viologen anchored to the GR enzyme. (Figure taken with permission from ref ${ }^{[97]}$ ).

In a further development of the modified photobiocatalytic GR enzymatic system, GR conveniently modified by pyridinium ions was immobilized in a crosslinked redox copolymer obtained by copolymerization of acrylamide and a bipyridinium having also an acrylamidopropyl unit in one of the nitrogen atoms (Scheme 28 ). In this assembly of redox copolymer containing modified GR, the operation of an electron transfer from EDTA to GSSG was proposed to occur through the redox polymer backbone and modified enzyme.

Other alternative systems to activate native GR for photocatalytic GSSG reduction have been accomplished using carboxyalkyl bipyridiniums attached to polylysine, the latter component acting as electron relay. It was found that the ability of the enzyme to perform GSSG reduction depends on the tether length connecting the bipyridinium units and the polymer. Transient absorption spectroscopy shows that the electron transfer rate from the bipyridinium electron relay to the enzyme is controlled by the length of the tether connecting bipyridinium and the polymer, long chains enhancing the electron transfer rate.

\section{Photobiocatalysis in living systems.}

In the context of determining the potential effects of nanomaterials in plants, one interesting observation has been that anatase $\mathrm{TiO}_{2} \mathrm{NPs}$ affect markedly to living spinach plants by increasing the vigor in aged sites and promoting chlorophyll formation leading to faster growth and higher development of the plant. ${ }^{[98]}$ This effect of $\mathrm{TiO}_{2}$ as small size NPs was presumed to derive from their photobiocatalytic activity. In fact, more detailed studies have 
shown that anatase $\mathrm{TiO}_{2} \mathrm{NPs}$ promote $\mathrm{CO}_{2}$ assimilation in living spinach plants. Purification of Rubisco by electrophoresis in $\mathrm{TiO}_{2} \mathrm{NP}$-treated spinachs and comparison with the same enzyme in controls has found that the activity of $\mathrm{TiO}_{2} \mathrm{NP}$ treated spinach Rubisco was 2.67 times higher than that of Rubisco from the control. Rubisco is a protein that is present in the chloroplast and is responsible for photosynthetic $\mathrm{CO}_{2}$ assimilation by catalyzing the reaction of $\mathrm{CO}_{2}$ with ribulose-1.5-biphosphate leading to two molecules of D-phosphoglyceric acid.

Characterization of the secondary structure of Rubisco from $\mathrm{TiO}_{2}$ NP-treated spinach showed that its structure is very different from that of Rubisco present in untreated spinach plants. This seems to indicate that the presence of $\mathrm{TiO}_{2} \mathrm{NPs}$ induces changes in natural spinach Rubisco and these induced changes are responsible for the observed benefits in the plant. Characterization of this Rubisco fraction shows that $\mathrm{TiO}_{2} \mathrm{NPs}$ activate the formation of a complex of Rubisco and Rubisco activase, this complex being responsible for the effects observed in the growth of spinach promoted by $\mathrm{TiO}_{2} \mathrm{NPs}$ (Scheme 29).

SPINACH

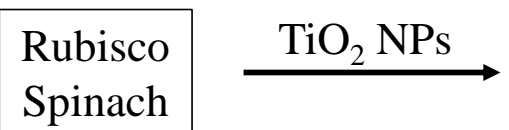

\section{SPINACH}

Rubisco- Rubisco
activase
complex

- Enhanced plant growth

- High $\mathrm{CO}_{2}$ assimilation

Scheme 29. Consequences of the addition of $\mathrm{TiO}_{2} \mathrm{NPs}$ to living spinaches.

\section{Conclusions}

Photocatalysis is a field experiencing a renewed interest, since besides degradation of pollutants in air and water, it can be applied to the production of solar fuels. At the present the efficiency of many photocatalytic processes is still very low and far from application. Aimed at increasing this low yields and inspired in Nature, a promising approach that is currently at the early stages of investigation could be the combination of photocatalysis and enzymes, leading to photobiocatalysis. Since enzymes are the perfect catalysts under physiological conditions, the points to be improved are related to the charge transfer from the photocatalyst and the intrinsic efficiency of charge separation at the photocatalysts. At the moment, most of the examples reported on photobiocatalysts employ $\mathrm{TiO}_{2}$, but certainly other efficient photocatalysts including perovskites, chalcogenides, nitrides, double layered hydroxides and graphenic materials are worth to be used in the preparation of photobiocatalysts. 
Besides expanding the type of semiconductors, communication of the photocatalyst and the enzyme requires of a general conceptual framework of how to couple both components. Examples have been presented of the several possibilities described to transfer electrons or holes from the semiconductor to the enzyme including direct attachment of the two components, but generally cofactors and more frequently cofactors and mediators a needed. The use of rhodium organometallic complexes that are the ubiquitous electron relays are unsatisfactory for any commercial application.

From biomimicking of photosynthetic centers, a step forward would be to move towards bioinspiration in which the knowledge on the operation of the natural systems can lead to the development of efficient photobiocatalytic systems in which the enzyme could be satisfactorily substituted by a suitable copy of the active center embedded or not on a polymer.

Due to the potential impact of photobiocatalysis, there is no doubt that the field will continue to grow in the near future and all these issues will be investigated with the long term goal of achieving more efficient artificial systems that could be commercially applicable for solar fuel production or pollutant degradation.

\section{Acknowledgements.}

Financial support by the Spanish Ministry of Economy and Competitiveness (Severo Ochoa and CTQ2012-32315) is gratefully acknowledged. J.A.M.-A. acknowledges the assistance of the CSIC for their award of a Postdoctoral JAE-Doc contract.

\section{References}

[1] R. Razeghifard and Editor, Natural and Artificial Photosynthesis: Solar Power as an Energy Source, John Wiley \& Sons, Inc., 2013, p. 462 pp.

[2] J. H. Kim, D. H. Nam and C. B. Park, Current Opinion in Biotechnology 2014, 28, $1-9$.

[3] A. Kudo, H. Kato and I. Tsuji, Chem. Lett. 2004, 33, 1534-1539.

[4] K. Maeda, M. Higashi, D. Lu, R. Abe and K. Domen, J. Am. Chem. Soc. 2010, 132, 5858-5868.

[5] E. Churakova, M. Kluge, R. Ullrich, I. Arends, M. Hofrichter and F. Hollmann, Angew. Chem., Int. Ed. 2011, 50, 10716-10719, S10716/10711-S10716/10711.

[6] K. Gurunathan, J. Mol. Catal. A: Chem. 2000, 156, 59-67.

[7] S. H. Lee, J. H. Kim and C. B. Park, Chemistry 2013, 19, 4392-4406.

[8] P. J. Dittmer, J. G. Miranda, J. A. Gorski and A. E. Palmer, J. Biol. Chem. 2009, 284, 16289-16297.

[9] S. Verma, A. K. Mishra and J. Kumar, Acc. Chem. Res. 2010, 43, 79-91. 
[10] L. Amalric, C. Guillard and P. Pichat, Research on Chemical Intermediates 1994, 20, 579-594.

[11] S. H. Lee, D. H. Nam, J. H. Kim, J. O. Baeg and C. B. Park, Chembiochem 2009, 10, 1621-1624.

[12] S. H. Lee, Y. C. Kwon, D. M. Kim and C. B. Park, Biotechnol Bioeng 2013, 110, 383-390.

[13] S. H. Lee, D. H. Nam and C. B. Park, Advanced Synthesis \& Catalysis 2009, 351, 2589-2594.

[14] M. Lee, J. U. Kim, J. S. Lee, B. I. Lee, J. Shin and C. B. Park, Adv Mater 2014, 26, 4463-4468.

[15] S. H. Lee, H. J. Lee, K. Won and C. B. Park, Chemistry 2012, 18, 5490-5495.

[16] H. J. Lee, S. H. Lee, C. B. Park and K. Won, Chem Commun (Camb) 2011, 47, 12538-12540.

[17] J. H. Kim, S. H. Lee, J. S. Lee, M. Lee and C. B. Park, Chem Commun (Camb) 2011, 47, 10227-10229.

[18] D. H. Nam and C. B. Park, Chembiochem 2012, 13, 1278-1282.

[19] M. A. Fox and M. T. Dulay, Chem. Rev. 1993, 93, 341-357.

[20] M. R. Hoffmann, S. T. Martin, W. Choi and D. W. Bahnemann, Chem. Rev. (Washington, D. C.) 1995, 95, 69-96.

[21] A. L. Linsebigler, G. Lu and J. T. Yates, Jr., Chem. Rev. (Washington, D. C.) 1995, 95, 735-758.

[22] A. Mills and S. Le Hunte, J. Photochem. Photobiol., A 1997, 108, 1-35.

[23] P. V. Kamat, J. Phys. Chem. Lett. 2011, 2, 242-251.

[24] R. Leary and A. Westwood, Carbon 2011, 49, 741-772.

[25] Q. Xiang, J. Yu and M. Jaroniec, Chem. Soc. Rev. 2012, 41, 782-796.

[26] H. Zhang, X.-J. Lv, Y.-M. Li, Y. Wang and J.-H. Li, ACS Nano 2010, 4, 380-386.

[27] H. Tang, C. M. Hessel, J. Wang, N. Yang, R. Yu, H. Zhao and D. Wang, Chem.

Soc. Rev. 2014, 43, 4281-4299.

[28] M.-Q. Yang, N. Zhang and Y.-J. Xu, ACS Appl. Mater. Interfaces 2013, 5, 11561164.

[29] N. Zhang, Y. Zhang, M.-Q. Yang, Z.-R. Tang and Y.-J. Xu, J. Catal. 2013, 299, 210-221.

[30] H. Imahori and Y. Sakata, Eur. J. Org. Chem. 1999, 2445-2457.

[31] H. Imahori, K. Tamaki, D. M. Guldi, C. Luo, M. Fujitsuka, O. Ito, Y. Sakata and S. Fukuzumi, J. Am. Chem. Soc. 2001, 123, 2607-2617.

[32] D. Kuciauskas, S. Lin, G. R. Seely, A. L. Moore, T. A. Moore, D. Gust, T. Drovetskaya, C. A. Reed and P. D. W. Boyd, J. Phys. Chem. 1996, 100, 15926-15932.

[33] N. V. Tkachenko, L. Rantala, A. Y. Tauber, J. Helaja, P. H. Hynninen and H. Lemmetyinen, J. Am. Chem. Soc. 1999, 121, 9378-9387.

[34] C. Gomes Silva, R. Juárez, T. Marino, R. Molinari and H. García, Journal of the American Chemical Society 2011, 133, 595-602.

[35] H. Ago, K. Petritsch, M. S. P. Shaffer, A. H. Windle and R. H. Friend, Adv. Mater. (Weinheim, Ger.) 1999, 11, 1281-1285.

[36] P. Avouris, Z. Chen and V. Perebeinos, Nat. Nanotechnol. 2007, 2, 605-615.

[37] P. Avouris, M. Freitag and V. Perebeinos, Nat. Photonics 2008, 2, 341-350.

[38] E. Kymakis and G. A. J. Amaratunga, Appl. Phys. Lett. 2002, 80, 112-114.

[39] M. Latorre-Sanchez, A. Primo and H. Garcia, Angew Chem Int Ed Engl 2013, 52, 11813-11816.

[40] S. Das Sarma, S. Adam, E. H. Hwang and E. Rossi, Rev. Mod. Phys. 2011, 83, 407-470. 
[41] M. Liu, X. Yin, E. Ulin-Avila, B. Geng, T. Zentgraf, L. Ju, F. Wang and X. Zhang, Nature (London, U. K.) 2011, 474, 64-67.

[42] T. O. Wehling, K. S. Novoselov, S. V. Morozov, E. E. Vdovin, M. I. Katsnelson, A. K. Geim and A. I. Lichtenstein, Nano Lett. 2008, 8, 173-177.

[43] G. Williams and P. V. Kamat, Langmuir 2009, 25, 13869-13873.

[44] S. Choudhury, J. O. Baeg, N. J. Park and R. K. Yadav, Angew Chem Int Ed Engl 2012, 51, 11624-11628.

[45] C. B. Park, S. H. Lee, E. Subramanian, B. B. Kale, S. M. Lee and J. O. Baeg, Chem Commun (Camb) 2008, 5423-5425.

[46] S. H. Lee, G. M. Ryu, D. H. Nam, J. H. Kim and C. B. Park, ChemSusChem 2014, 7, 3007-3011.

[47] D. H. Nam, S. H. Lee and C. B. Park, Small 2010, 6, 922-926.

[48] J. S. Lee, S. H. Lee, J. H. Kim and C. B. Park, Lab Chip 2011, 11, 2309-2311.

[49] S. H. Lee, J. Ryu, D. H. Nam and C. B. Park, Chem Commun (Camb) 2011, 47, 4643-4645.

[50] C. Aprile, A. Corma and H. Garcia, Phys Chem Chem Phys 2008, 10, 769-783.

[51] L. Vayssieres, C. Sathe, S. M. Butorin, D. K. Shuh, J. Nordgren and J. Guo, $A d v$.

Mater. (Weinheim, Ger.) 2005, 17, 2320-2323.

[52] R. Wang, J. H. Xin, Y. Yang, H. Liu, L. Xu and J. Hu, Appl. Surf. Sci. 2004, 227, 312-317.

[53] J. P. Wilcoxon, P. P. Newcomer and G. A. Samara, J. Appl. Phys. 1997, 81, 79347944.

[54] G. K. Mor, K. Shankar, M. Paulose, O. K. Varghese and C. A. Grimes, Nano Lett. 2005, 5, 191-195.

[55] G. K. Mor, K. Shankar, M. Paulose, O. K. Varghese and C. A. Grimes, Nano Lett. 2006, 6, 215-218.

[56] G. K. Mor, O. K. Varghese, M. Paulose, K. Shankar and C. A. Grimes, Sol. Energy Mater. Sol. Cells 2006, 90, 2011-2075.

[57] J. H. Park, S. Kim and A. J. Bard, Nano Lett. 2006, 6, 24-28.

[58] F. Amano, T. Yasumoto, O.-O. Prieto-Mahaney, S. Uchida, T. Shibayama and B. Ohtani, Chem. Commun. (Cambridge, U. K.) 2009, 2311-2313.

[59] L. Gai, Q. Mei, X. Qin, W. Li, H. Jiang and X. Duan, Mater. Res. Bull. 2013, 48, 4469-4475.

[60] Z. Wei, E. Kowalska and B. Ohtani, Chem. Lett. 2014, 43, 346-348.

[61] O. K. Varghese, M. Paulose, T. J. LaTempa and C. A. Grimes, Nano Letters 2009, 9, $731-737$.

[62] S. Neatu, J. A. Macia-Agullo and H. Garcia, Int J Mol Sci 2014, 15, 5246-5262.

[63] J. Ryu, S. H. Lee, D. H. Nam and C. B. Park, Adv Mater 2011, 23, 1883-1888.

[64] H. Kato, K. Asakura and A. Kudo, J. Am. Chem. Soc. 2003, 125, 3082-3089.

[65] H. Kato and A. Kudo, J. Phys. Chem. B 2001, 105, 4285-4292.

[66] X. Zong, H. Yan, G. Wu, G. Ma, F. Wen, L. Wang and C. Li, J. Am. Chem. Soc. 2008, 130, 7176-7177.

[67] M. Mifsud, S. Gargiulo, S. Iborra, I. W. Arends, F. Hollmann and A. Corma, Nat Commun 2014, 5, 3145.

[68] J. Ryu, D. H. Nam, S. H. Lee and C. B. Park, Chemistry 2014, 20, 12020-12025.

[69] J. S. Lee, D. H. Nam, S. K. Kuk and C. B. Park, Chemistry 2014, 20, 3584-3588.

[70] Y. Zhao, J. R. Swierk, J. D. Megiatto, Jr., B. Sherman, W. J. Youngblood, D. Qin,

D. M. Lentz, A. L. Moore, T. A. Moore, D. Gust and T. E. Mallouk, Proc Natl Acad Sci

U S A 2012, 109, 15612-15616. 
[71] Y. S. Nam, A. P. Magyar, D. Lee, J.-W. Kim, D. S. Yun, H. Park, T. S. Pollom, D. A. Weitz and A. M. Belcher, Nat Nano 2010, 5, 340-344.

[72] Y. S. Nam, T. Shin, H. Park, A. P. Magyar, K. Choi, G. Fantner, K. A. Nelson and A. M. Belcher, Journal of the American Chemical Society 2010, 132, 1462-1463.

[73] J. H. Kim, D. H. Nam, Y. W. Lee, Y. S. Nam and C. B. Park, Small 2014, 10, 1272-1277.

[74] J. H. Kim, M. Lee, J. S. Lee and C. B. Park, Angew Chem Int Ed Engl 2012, 51, 517-520.

[75] W.-H. Ryu, Y. W. Lee, Y. S. Nam, D.-Y. Youn, C. B. Park and I.-D. Kim, Journal of Materials Chemistry A 2014, 2, 5610.

[76] J. H. Kim, M. Lee and C. B. Park, Angew Chem Int Ed Engl 2014, 53, 6364-6368.

[77] J. W. Ko, W. H. Ryu, I. D. Kim and C. B. Park, Chem Commun (Camb) 2013, 49, 9725-9727.

[78] M. Lee, J. H. Kim, S. H. Lee, S. H. Lee and C. B. Park, ChemSusChem 2011, 4, 581-586.

[79] Z. Bian, T. Tachikawa, P. Zhang, M. Fujitsuka and T. Majima, J. Am. Chem. Soc. 2014, 136, 458-465.

[80] H. G. Baldovi, F. Albarracin, P. Atienzar, B. Ferrer, M. Alvaro and H. Garcia, ChemPhysChem Ahead of Print.

[81] H. G. Baldovi, B. Ferrer, M. Alvaro and H. Garcia, J. Phys. Chem. C 2014, 118, 9275-9282.

[82] B. I. Ipe and C. M. Niemeyer, Angewandte Chemie-International Edition 2006, 45, 504-507.

[83] B. E. Conway and G. Jerkiewicz, Electrochimica Acta 2000, 45, 4075-4083.

[84] B. Kumar, M. Beyler, C. P. Kubiak and S. Ott, Chem. - Eur. J. 2012, 18, 12951298, S1295/1291-S1295/1211.

[85] E. Reisner, D. J. Powell, C. Cavazza, J. C. Fontecilla-Camps and F. A. Armstrong, Journal of the American Chemical Society 2009, 131, 18457-18466.

[86] S. Bae, E. Shim, J. Yoon and H. Joo, Solar Energy Materials and Solar Cells 2008, 92, 402-409.

[87] T. W. Woolerton, S. Sheard, E. Pierce, S. W. Ragsdale and F. A. Armstrong, Energy \& Environmental Science 2011, 4, 2393-2399.

[88] R. Goy, U.-P. Apfel, C. Elleouet, D. Escudero, M. Elstner, H. Goerls, J. Talarmin, P. Schollhammer, L. Gonzalez and W. Weigand, European Journal of Inorganic Chemistry 2013, 2013, 4466-4472.

[89] J.-X. Jian, Q. Liu, Z.-J. Li, F. Wang, X.-B. Li, C.-B. Li, B. Liu, Q.-Y. Meng, B. Chen, K. Feng, C.-H. Tung and L.-Z. Wu, Nature Communications 2013, 4.

[90] L. Chen, Z. Zhang, Y. Wang, Y. Guan, K. Deng, K. Lv, J. Sun, Z. Li and M. Li, Journal of Molecular Catalysis a-Chemical 2013, 372, 114-120.

[91] C. Orain, F. Quentel and F. Gloaguen, ChemSusChem 2014, 7, 638-643.

[92] P. Könst, S. Kara, S. Kochius, D. Holtmann, I. W. C. E. Arends, R. Ludwig and F. Hollmann, ChemCatChem 2013, 5, 3027-3032.

[93] R. Asahi, T. Morikawa, T. Ohwaki, K. Aoki and Y. Taga, Science (Washington, DC, U. S.) 2001, 293, 269-271.

[94] J. L. Gole, J. D. Stout, C. Burda, Y. Lou and X. Chen, J. Phys. Chem. B 2004, 108, 1230-1240.

[95] T. Ohno, M. Akiyoshi, T. Umebayashi, K. Asai, T. Mitsui and M. Matsumura, Appl. Catal., A 2004, 265, 115-121.

[96] Q. Shi, D. Yang, Z. Jiang and J. Li, Journal of Molecular Catalysis B-Enzymatic 2006, 43, 44-48. 
[97] I. Willner, N. Lapidot, A. Riklin, R. Kasher, E. Zahavy and E. Katz, Journal of the American Chemical Society 1994, 116, 1428-1441.

[98] F. Gao, F. Hong, C. Liu, L. Zheng, M. Su, X. Wu, F. Yang, C. Wu and P. Yang, Biological Trace Element Research 2006, 111, 239-253. 